\title{
LOS PRESBITERIANOS REVOLUCIONARIOS EN YUCATÁN. INSERCIÓN SOCIAL Y PARTICIPACIÓN POLÍTICA ${ }^{1}$
}

\author{
Ezer Roboam May May \\ Centro de Investigaciones y Estudios Superiores \\ en Antropología Social-Peninsular
}

\section{INTRODUCCIÓN}

- 2 historiografía consagrada del protestantismo mexicano ha la disidencia política - liberales radicales y movimientos revolucionarios - y la disidencia religiosa, es decir, con los masones y los espiritistas. En términos generales, estas alianzas fueron los antecedentes que marcaron la ruta del protestantismo hacia su participación revolucionaria. Es imposible negar la relación entre el protestantismo y la Revolución; los trabajos de McKechnie, ${ }^{2}$ Bastian $^{3}$ y Baldwin ${ }^{4}$ la han evidenciado notoriamente.

Fecha de recepción: 10 de febrero de 2017

Fecha de aceptación: 25 de octubre de 2017

\footnotetext{
${ }^{1}$ Agradezco a los evaluadores anónimos por las significativas sugerencias, las cuales coadyuvaron a elevar la calidad de este artículo.

2 McKechnie, "The Mexican Revolution and the national Presbyterian".

3 Bastian, Los disidentes.

4 Baldwin, Protestants and the Mexican Revolution.
} 
Dichas alianzas fueron enmarcadas por Bastian dentro del paradigma "sociedades de ideas", el cual remite a un perfil asociativo de inculcación de valores modernos, democráticos e igualitarios. ${ }^{5}$ Desde esta visión, se ha convenido decir que la difusión y la visibilización del protestantismo mexicano se dieron a través de los canales de estas sociedades de ideas disidentes, que en su momento actuaron como bloque contra el corporativismo político y religioso. ${ }^{6}$

Según Bastian, el caso de la difusión protestante en Yucatán no es excepcional, puesto que estuvo determinada por los rápidos cambios económicos y por la alianza con los grupos liberales marginados. ${ }^{7}$ Algunos historiadores han coincidido con la premisa bastiana de que el presbiterianismo yucateco formó parte del fenómeno asociativo liberal y moderno de los últimos años del siglo $\mathrm{XIX}^{8}$ y del periodo revolucionario de Salvador Alvarado. ${ }^{9}$ Estos argumentos nos conducen a pensar que el presbiterianismo en Yucatán sostuvo lazos estrechos y mutuamente benéficos con la disidencia religiosa (masones y espiritistas) y con la disidencia política (liberales radicales y revolucionarios).

Por un lado, si bien esta idea no se puede rebatir para la fase de inserción del presbiterianismo (1877-1897), sí debe matizarse para la etapa del alvaradismo, y es lo que me propongo describir en este texto. Sobre todo, que dicha perspectiva analítica se ha extendido al periodo constitucionalista, en el que los protestantes del centro del país tuvieron una importante injerencia política desde arriba y ya no sólo desde las bases cívicas y armadas. ${ }^{10}$

Por el otro, sostengo que estas relaciones no necesariamente determinaron su crecimiento. Esta hipótesis no se basa en la

\footnotetext{
5 BAstian, "El paradigma de 1789".

${ }^{6}$ Bastian, Los disidentes.

7 Bastian, Los disidentes, pp. 108-109, 117.

8 Martín, "Origen del protestantismo en Yucatán”.

9 Savarino, Pueblos y nacionalismo, pp. 248-251.

10 Bastian, Protestantismo y sociedad en México, pp. 105-167.
} 
negación del aumento numérico de protestantes, puesto que los censos de 1910 y 1921 demostraron un ostensible incremento en términos absolutos, de 1859 a 8145 personas; este intervalo fue el mayor de los registrados entre 1895 y $1950 .{ }^{11}$ Por el contrario, este crecimiento pudo ocurrir sin que se tuvieran que entablar vínculos estrechos con los grupos espiritistas y masones. Sin embargo, el abordaje de este aspecto abarcaría más espacio del disponible, ${ }^{12}$ por lo que me limito a exponer y explicar la marginalidad política del presbiterianismo durante el constitucionalismo alvaradista; eso sí, es necesario dilucidar que tuvo un papel significativo aunque no protagónico.

Parto de la afirmación de que la Revolución presentó diferentes expresiones, ritmos, matices e intensidades según las regiones. ${ }^{13}$ Por tanto, valdría la pena indagar cuáles fueron estos contrastes entre la relación del protestantismo, el liberalismo y la Revolución en Yucatán. ${ }^{14}$ Así también es necesario reflexionar sobre los factores que generaron similitudes con el perfil nacional protestante.

Siguiendo esta línea de ideas, las preguntas que estructuran este artículo son: ¿cómo fue la participación de los presbiterianos yucatecos durante la revolución constitucionalista dentro y fuera de la capital Mérida? Así mismo, ¿en qué medida se manifestaron las alianzas con las heterodoxias religiosas? ¿El

11 May May, "Presbiterianos en Yucatán”, pp. 314-316.

12 En la tesis de mi autoría desarrollo este argumento con base en múltiples casos del área rural y en el análisis microhistórico de un pueblo ubicado al sur del estado. Véase MaY MaY, "Presbiterianos en Yucatán”.

13 BaIley, "Revisionism and the Recent Historiography; Carr, "Recent Regional Studies of the Mexican Revolution".

14 Por un lado, Yucatán frente al fenómeno de la revolución mexicana ha jugado un papel paradigmático en la historiografía referente al tema de las haciendas, de los peones y de las movilizaciones de los subalternos; incluso, después de Tabasco, Yucatán fue el otro “laboratorio de la Revolución”. Por el otro, en el aspecto de la religión también presenta matices, tales como la inaplicable contraposición Iglesia-liberalismo y las inexistentes revueltas populares en oposición a Porfirio Díaz relacionadas e impulsadas por el protestantismo. Véase SAVARINo, "Yucatán: ¿un caso atípico”. 
constitucionalismo les otorgó las mismas prerrogativas políticas que a sus homólogos del centro del país? ¿Los presbiterianos necesariamente adoptaron la visión revolucionaria sobre las haciendas? No obstante, quedo a deber al lector el análisis del posible papel que el auge henequenero pudo tener en la difusión y el crecimiento del protestantismo; en el último apartado sólo ofrezco pistas de este tema obligado.

\section{ESTABLECIMIENTO DE LA PRIMERA IGLESIA}

PRESBITERIANA

Durante el siglo xIx, la Iglesia católica tuvo una gran influencia en el ámbito civil, militar y artístico en la ciudad de Mérida, en el que ni siquiera los católicos liberales, como los sanjuanistas, lograron imponerse en el ámbito político-religioso. ${ }^{15} \mathrm{Las}$ Leyes de Reforma pudieron oírse en algunos espacios públicos, pero tampoco lograron resonar o mantenerse en las reglas del gobierno. Incluso, Francisco Arredondo, quien aprobó en 1844 la compra de mil ejemplares del Nuevo Testamento, fue uno de los que apoyaron la devolución del seminario al clero, logrando concretarse dicha devolución con el apoyo del yerno de Benito Juárez, Contreras Elizalde. Por tanto, la Iglesia católica continuó con una posición privilegiada en Yucatán a pesar de la Reforma. ${ }^{16}$

Con la llegada de Díaz a la presidencia, Protasio Guerra fue designado gobernador en 1877 , en el que su posición fue

15 Los sanjuanistas, junto con Lorenzo de Zavala, fueron un grupo que luchó por el reconocimiento de la Constitución de Cádiz. Para ellos el régimen colonial significó un obstáculo para el desarrollo social y económico del sector social al que pertenecía, por lo cual, algunas de las reivindicaciones de este grupo católico liberal eran el fin de los privilegios del clero y la devolución de las tierras a los indígenas. Consúltese Mantilla, "El pensamiento sanjuanista"; Álvarez, "Hacer patria sin indios".

16 Baqueiro, Historia del antiguo Seminario Conciliar, pp. 4-8; Menéndez, Iglesia y poder, pp. 27-30. 
adversa hacia los políticos liberales aliados a algunas facciones del clero. Estas condiciones permitieron que entre marzo y mayo del mismo año, el masón Agustín del Río subiera al poder como gobernador interino. ${ }^{17}$ Por tanto, la masonería junto con el espiritismo ${ }^{18}$ tuvieron auge en la capital yucateca para estos años, y para el obispo Leandro Rodríguez era clara la influencia de éstos en la vida religiosa de los meridanos, en tanto percibía la decreciente observancia de los ritos y sacramentos católicos. Con lamento y desesperanza exclama: “¿qué tiene ya de extraño el ver propagados en los pueblos de nuestra amada diócesis los más crasos y monstruosos errores, como son los del libre pensamiento, los de la masonería y espiritismo?". ${ }^{19}$

Es muy probable que el misionero presbiteriano Maxwell Phillips estuviera informado de estas transformaciones sociopolíticas a través de la correspondencia sostenida entre el periódico protestante La Antorcha Evangélica y el diario espiritista yucateco La Ley de Amor. ${ }^{20}$ Posiblemente, el "monitoreo" de las condiciones de Mérida iniciaron desde principios de la década de 1870, pues Phillips había expresado su interés preferencial por Mérida como campo misionero en una carta fechada el 26 de abril de $1873 .{ }^{21}$ Meses después de la publicación de la carta pastoral del obispo Rodríguez, se sumaría a los "monstruosos errores" la propagación del protestantismo.

Y así fue, la prensa católica ya auguraba la pronta amenaza protestante en Yucatán; en 1874 se describía esta "amenaza”

\footnotetext{
17 Menéndez, Iglesia y poder, pp. 65, 57-58.

${ }^{18}$ El primer círculo espiritista en Mérida se conformó en noviembre de 1874 y se llamó "Peralta”. ArgüElles, "El protestantismo en Yucatán”, p. 47.

19 BY, FR, Folletería, "Octava Carta Pastoral que el Ilmo. Sr. Obispo Dr. D. Leandro Rodríguez de la Gala dirige al venerable clero y fieles de su Diócesis, 23 de marzo de 1877 ”, p. 8.

${ }^{20}$ Este periódico espiritista empezó a publicarse en 1876; su primer editor fue Rodulfo G. Cantón.

${ }^{21}$ Bastian, "La penetración de las sociedades protestantes", p. 9; Martín, "Origen del protestantismo en Yucatán”, p. 125.
} 
como el "monstruo de tres cabezas": masonería, espiritismo y protestantismo. Las dos primeras apoyaron con elogios la llegada de Phillips a Mérida a fines de octubre de 1877, expresándose en periódicos como La Ley de Amor, El Porfirista y El Periódico Oficial, ${ }^{22}$ siendo el periódico espiritista La Ley de Amor el mejor referente de este acontecimiento:

El Rev. Sr. Phillips se halla en Mérida en unión de su apreciable familia, este ilustrado redactor de "La Antorcha” periódico protestante que se publica en Zacatecas. Deseamos que su permanencia en esta capital le sea grata y conserve siempre buenos recuerdos de la cultura e ilustración de los yucatecos. Nosotros, que respetamos sinceramente todas las creencias y amamos a todas las personas que dedican sus tareas al bien de la humanidad, saludamos amigablemente al Sr. Rev. Maxwell Phillips y a su apreciable familia. ${ }^{23}$

El misionero y su familia habitaron en la calle $3^{\text {a }}$ de Porfirio Díaz, núm. 23, es decir, en la "esquina vulgarmente llamada ' $\mathrm{La}$ Perdiz', hoy cruzamiento de las calles 54 y 59”, en donde inició la circulación de Biblias, Nuevos Testamentos y de porciones bíblicas entre sus allegados; el 19 de mayo de 1878 decidió celebrar cultos de predicación, a los que asistieron, según, numerosas personas. Miembros del periódico espiritista asistieron a este primer culto y lo describieron como coyuntural, considerando que muchos meridanos se habían "sacudido las cadenas del dogmatismo religioso" y que éstos no sabían "a qué atenerse en punto a creencias religiosas" ${ }^{24}$

22 BY, FR, La Caridad, 15-01-1874, p. 2; BSTPM, EF, 15-11-1901, portada.

23 BY, FR, La Ley de Amor, 23-11-1877, p. 168. Esta fuente también es citada en MARTín, “Origen del protestantismo en Yucatán”, pp. 126-127, y en ARGÜELLES, “El protestantismo en Yucatán”, p. 61.

24 BY, FR, La Ley de Amor, 01-06-1878, p. 88. Esta referencia también es citada por MARTín, “Origen del protestantismo en Yucatán”, p. 128. 
Por otro lado, el acontecimiento del culto evangélico desató críticas de la prensa católica, mientras la liberal manifestó su apoyo, aduciendo que los "romanistas" incitaban actos de violencia exaltando el fanatismo. En este mismo año, el periódico conservador El Semanario Yucateco expresó que la entrada del protestantismo en México era reflejo del sentir expansionista del vecino del norte, y por tanto el protestantismo pasaba a ser una estrategia para conquistar el territorio mexicano en miras de su anexión a Estados Unidos de América. ${ }^{25}$

Phillips también participó en el debate de la prensa atacando las celebraciones del catolicismo popular, en este caso de la fiesta patronal del barrio de Santiago. Estas fiestas religiosas fueron descritas por él como "bárbara costumbre" y "perniciosa diversión"; estaba claro que para el misionero el propósito del evangelio protestante era la "moralización” y "civilización" de la sociedad yucateca. ${ }^{26}$ No obstante, Phillips tuvo que abandonar Yucatán debido a la muerte de sus dos hijos, causada por la fiebre amarilla.

Para Crescencio Carrillo y Ancona fue suficiente la llegada de Phillips para poner en alerta a sus feligreses; por tanto, el 11 de junio de 1885 publicó un edicto contra la propaganda protestante que se estaba llevando a cabo en Mérida. Seguramente, también supo de la presencia del colportor español Manuel Francisco Fernández, representante de la agencia mexicana de la Sociedad Bíblica Americana (sBA), quien estableció su venta de libros y folletos frente al portal de granos, "en los corredores de la casa del comerciante Manuel Pinelo Montero". ${ }^{27}$

A pesar de las circunstancias, gracias a la labor del colportor, junto con la del obrero Procopio C. Díaz, pudo inaugurarse el 15 de noviembre de 1885 la iglesia evangélica El Divino Salvador, siendo el fundador el "controvertido" Fernández. ${ }^{28}$ Un día antes

\footnotetext{
BY, FR, El Semanario Yucateco, 03-08-1878, p. 1.

${ }_{26}$ Martín, “Origen del protestantismo en Yucatán”, pp. 130-131.

27 SuÁrez, Historia del obispado, p. 1113.

${ }_{28}$ BSTPM, EF, 15-08-1913, p. 498.
} 
de la inauguración, El Amigo del País advirtió sobre este hecho, e hizo saber que el propósito principal de la fundación del templo protestante es "engañar a las clases poco ilustradas de la sociedad". ${ }^{29}$ En esa ocasión el misionero Joseph Milton Greene formalizó la inauguración del templo, ${ }^{30}$ la que por la expresada decepción de la prensa católica puede inferirse que fue muy concurrida, especialmente por los liberales; en la prensa se invitó a éstos a la reflexión sobre "el oscuro porvenir que espera a la patria si llega el protestantismo a cimentarse entre nosotros". ${ }^{31}$

Los presbiterianos le debían su establecimiento al apoyo de los liberales locales; por tanto, tenían que corresponder de alguna forma al proyecto republicano, como sería la exaltación de los héroes locales. La figura referenciada fue la del general Manuel Cepeda Peraza, conocido como defensor de la idea de república promovida por Juárez y como uno de los principales libertadores de la invasión imperialista en territorio yucateco. El 3 de marzo de 1886, la Iglesia presbiteriana celebró un "culto extraordinario y funeral solemne" con motivo del $17^{\circ}$ aniversario de la muerte del general Cepeda; ${ }^{32}$ éste fue un claro saludo de respaldo a los dirigentes gubernamentales del momento, como Octavio Rosado y Guillermo Palomino, quienes fueron colaboradores del juarismo en su momento. Esta fue una forma inicial de acomodación social, la cual buscaba la colaboración del gobierno y no la afrenta. Asimismo, el ministro Procopio C. Díaz llevó las actividades de la Iglesia en esta dirección, pues como militar liberal compartía la experiencia biográfica con la de los dos gobernantes antes nombrados. ${ }^{33}$

\footnotetext{
29 BY, FR, El Amigo del País, 14-11-1885, p. 1.

30 Martín, Historia de la Iglesia presbiteriana, p. 34.

31 BY, FR, El Amigo del País, 21-11-1885, p. 1.

32 Martín, “Origen del protestantismo en Yucatán”, p. 137.

33 Estos personajes sirvieron como militares en la Guerra de Reforma y en la batalla de la intervención francesa; la breve síntesis biográfica de Procopio
} 
$\mathrm{Al}$ año siguiente, P. C. Díaz fue sustituido por el misionero Joseph Milton Greene y el ministro Vicente Hurtado; este misionero "no menos fino que el señor Phillips, halló acogida sincera entre las personas prominentes de la sociedad, como los señores Ramón y Alonso Aznar (este último digno padre del Lic. Alonso Aznar Mendoza, hoy magistrado en la Suprema Corte de la Nación) y personas de nuestra particular amistad, quienes impartieron una ayuda muy eficaz" ${ }^{34}$ a Greene. Hasta el momento se ha creído que ambos sujetos eran hermanos, ${ }^{35}$ pero lo cierto es que fueron tío y sobrino, respectivamente. El padre de Alonso Aznar Dondé fue hermano mayor de Ramón Aznar Pérez, estando esta familia en constante contacto con las lecturas extranjeras y con todo lo relacionado a las ciencias y el arte - por ejemplo, Alonso tenía un expendio de semillas y plantas en la ciudad-. Pero además de estos gustos personales y culturales, Manuel Dondé Cámara, tío materno de Alonso, ${ }^{36}$ junto con Carlos Peón Machado fueron republicanos reconocidos en Yucatán. ${ }^{37}$ El protestantismo en México había demostrado este rostro político a la sociedad en general, y siendo además un modelo cercano al estadounidense - con el que esta familia tenía contacto a través de la industria de la imprenta-, resultó ser más atractivo para individuos con este perfil sociocultural y político.

Durante el periodo de 1885-1893, la membresía de la Iglesia presbiteriana ascendió a 49 bautizados. Aunque no tenemos datos certeros de la membresía de dicha iglesia durante esos años, supongo que se mantuvo sin movimientos significativos

\footnotetext{
C. Díaz puede verse en Martín, Historia de la Iglesia presbiteriana, p. 33 y “Origen del protestantismo en Yucatán”, p. 131.

${ }^{34}$ BSTPM, EF, diciembre-1935, p. 23.

35 A juzgar por la referencia hecha por Martín, "Origen del protestantismo en Yucatán”, p. 138.

${ }^{36}$ Los árboles genealógicos de estos personajes pueden consultarse en la base de datos del proyecto "Familias novohispanas. Un sistema de redes". Disponible en línea: http://gw.geneanet.org/sanchiz

37 Menéndez, Iglesia y poder, p. 61.
} 
ascendentes, pues para 1893, cuando Alfonso Herrera retoma el liderazgo se continuó el registro de los citados 49 miembros. Pero como él mismo afirmó, la iglesia despertó con ímpetu después de haber estado dormida por varios años. Aun así, puede decirse que la corriente liberal sí engrosó las filas presbiterianas, pero sólo se trató de una afinidad electiva; todavía no podía hablarse de un compromiso real con las creencias y la organización religiosa.

Otro factor favorable para el desarrollo protestante fue el ascenso de Carlos Peón Machado a la gubernatura de Yucatán en 1894, el cual implementó una política más rigurosa contra el clero, prohibiendo la enseñanza de los dogmas católicos en las escuelas. No obstante, esto no significó que algunos sectores católicos no atentaran contra los miembros presbiterianos; simplemente el gobierno de Peón fue menos intransigente con las peticiones de los protestantes. Verbigracia, la solicitud que Herrera realizó al gobernador el 19 de marzo de 1894:

Protegiendo las leyes de la nación, la libertad de cultos, hemos abierto en esta ciudad una Iglesia Evangélica, cuyo fin es la regeneración moral de las masas; mas siendo miradas y molestadas por algunos seres de creencias opuestas, me dirijo al primer magistrado del Estado pidiendo se nos conceda un guarda del orden público para que vigile la completa paz en los días y horas en que celebramos nuestras reuniones. A más avanza mi súplica; siendo no tan solamente molestados en grupo compacto sino en persona, pido se me dé el privilegio de una seguridad personal para que las autoridades superiores e inferiores, puedan dar su auxilio sin escusa en caso de ataque a mi persona. ${ }^{38}$

El gobernador Peón aceptó dicha petición el mismo día y dijo no haber "autoridad superior e inferior que le niegue auxilios en

38 AGEY, PE, G, C, c. $285,1894$. 
caso de ataque a su persona”. Los policías fueron notificados para situar vigilancia en los alrededores del templo evangélico.

Desde este mismo año, la organización interna estaba tomando más forma y fuerza con la creación de la Sociedad del Esfuerzo Cristiano conformada por jóvenes en 1894, la fundación de la Sociedad de Señoras impulsada por la esposa de Herrera en 1896, así como de la sociedad infantil Bethlem. ${ }^{39}$ Esta estructuración permitió que a partir del 20 de abril de 1896 iniciara la recaudación de los fondos necesarios para la edificación del templo, logrando dicho fondo en marzo de 1898, por lo que el 23 de abril de este mismo año "los albañiles comenzaron a demoler el antiguo edificio y a poner los cimientos del nuevo templo". 40

Durante los años subsiguientes, la iglesia presbiteriana fue impulsada por Herrera; sin embargo, su posición dentro de la organización nacional ocasionó sus constantes salidas para laborar temporalmente en campos foráneos, como en el norte del país. En la 14ª reunión del Presbiterio del Golfo en 1909 se solicitó que un ministro llamado Lisandro Cámara se encargase de la iglesia de Mérida en ausencia del pastor Herrera durante los meses de junio a diciembre; no obstante, en esos mismos años, el obrero Plácido Lope trabajaba junto con su esposa en la evangelización en los pueblos de Yucatán. Esta labor proselitista le otorgó a Lope una buena imagen frente a los miembros de las distintas iglesias yucatecas; las amistades que entabló fueron amplias. Por tanto, meses después de ser ordenado al santo ministerio en 1909, la iglesia de Mérida consideró hacerle el "llamamiento" para que se hiciera cargo del pastorado de esta misma, y como "el trabajo es de mucha importancia, debido al espíritu evangelista y trabajador que reina entre estos hermanos, desean completar los arreglos a la mayor brevedad posible para entregarse de lleno a su misión de propaganda"; pero hasta el

39 Martín, “Origen del protestantismo en Yucatán”, p. 147.

40 BSTPM, EF, 15-01-1899, pp. 12-13. 
mes de mayo Lope fue instalado como pastor de la iglesia local. ${ }^{41}$ Con el fin del periodo de Herrera, la iglesia inició una nueva etapa teniendo a Lope como líder, y él es quien viviría el porvenir del presbiterianismo durante la Revolución en Yucatán.

\section{LA REVOLUCIÓN ANTICIPADA.}

ALGUNAS AFINIDADES

En este apartado quisiera tratar tres aspectos que evidenciaron el programa revolucionario años antes del arribo del general Eleuterio Ávila en 1914 y del constitucionalista Salvador Alvarado en 1915: 1) antialcoholismo y temperancia, 2) programa educativo y 3) la prensa crítica antioligárquica. Estos tres elementos fueron muy importantes para compaginar con el programa alvaradista.

\section{Antialcobolismo y temperancia}

Desde la llegada de las misiones protestantes a México, el alcoholismo fue un obstáculo a vencer en la sociedad mexicana, y llegó a ser más importante que la inculcación de las doctrinas y ritos. El discurso utilizado por el protestantismo para convencer sobre la nocividad del alcohol fue el de la medicina científica. ${ }^{42}$ El protestantismo en Mérida no fue la excepción en la combinación antialcoholismo-medicina. El presbiteriano Maximiliano R. Medina Samada es el mejor ejemplo; Samada fue editor de la Revista de Especialidades Médicas y del periódico Regeneración Social, los cuales se publicaron desde 1911, este último "destinado a la propaganda de las ideas de Temperancia".

En cierto modo, este impulso desde el presbiterianismo provino de Natalia Salcedo, esposa de Herrera, que pertenecía

${ }^{41}$ BSTPM, EF, 14-05-1909, p. 283; 12-11-1909, p. 722; 27-05-1910, p. 337.

42 Bastian, Historia del protestantismo, pp. 126-127; VeGA, "La óptica metodista en la divulgación". 
a la Sociedad Nacional de Temperancia; ${ }^{43}$ sin embargo, Medina tuvo un papel relevante como agente en la Sociedad Yucateca de Temperancia. El periódico Regeneración Social tuvo vida hasta el año 1914, teniendo como fin promover la "abstinencia alcohólica”. ${ }^{44}$ Incluso, con la ayuda de algunos presbiterianos lograron prohibir en Mérida la venta de alcohol el domingo de Carnaval en $1913 .{ }^{45}$

Esta formación educativa e intelectual de Medina también la ejerció dentro de la Iglesia: con el cargo de anciano gobernante impartía conferencias antialcohólicas, médicas y de puericultura a los miembros de la iglesia y a los profesores de la Escuela Dominical. Evidentemente éste era el perfil de individuos que la Revolución buscaba para mejorar a la sociedad; por ejemplo, una misma conferencia impartida en el templo también fue ofrecida en la Escuela Normal Mixta del Estado por invitación del director Luis Urzaiz en 1918. ${ }^{46}$ La Ley Seca y la erradicación de los vicios fueron una de las tareas principales del gobierno revolucionario, y los presbiterianos ya estaban familiarizados con estas acciones desde un par de años antes.

Desde el arribo de Salvador Alvarado en 1915, las líneas principales de acción fueron las prohibiciones relativas a la prostitución, a las corridas de toros y al alcohol; Alvarado creía que el alcoholismo era una de las debilidades de Yucatán. Pero el carácter apresurado contra estas costumbres lo llevaron al fracaso, ocasionando la clandestinidad de la venta de alcohol. ${ }^{47}$

El gobierno revolucionario de Alvarado trasladó las ideas antialcohólicas al ámbito secular, mientras los presbiterianos en Yucatán, debido a una frecuente comunicación con las iglesias del centro, implementaron desde cinco años antes estas

43 Martín, “Experiencias de las asociaciones femeniles”, p. 78.

44 BY, FR, Regeneración Social, 01-08-1911, p. 1;01-01-1914, p. 1.

45 BSTPM, EF, 04-04-1913, p. 197.

46 BSTPM, EF, 24-05-1918, p. 334.

47 Joseph, Revolución desde afuera, pp. 132-133. 
medidas contra el alcoholismo; parte de estos vasos comunicantes fueron las reuniones presbiteriales, como es el caso de la reunión del Presbiterio del Golfo de 1910, donde se "recomendó la obra de temperancia contra la embriaguez, los toros y los gallos, tanto por el precepto, como por el ejemplo de los cristianos evangélicos" ${ }^{48} \mathrm{Y}$ así fue ejecutado en la iglesia de Mérida y en las congregaciones de Ticul, Muna y Progreso, las cuales constantemente informaban de este tipo de actividades desde 1910.

En estos casos, resalta el acto realizado en Progreso el domingo 13 de noviembre de 1910, un día de "estudio universal de temperancia", en el que se describió al alcohol como "enemigo acérrimo del adelanto moral, intelectual y físico de la raza humana”. El ministro Aurelio Maldonado, quien dirigió la reflexión bíblica sobre la nocividad del alcoholismo, lo relata de la siguiente manera:

Después de una larga meditación, hasta en donde pudiéramos alcanzar sobre el tema, de que el uso del alcohol perjudica la salud, deshonra el hogar y afrenta a Dios, él que escribe, para no dejar evaporarse lo que en el púlpito sagrado se había expuesto, hizo una cordial invitación a todos los que han sentido el yugo del funesto alcohol. En seguida levantaron la mano 15 personas, demostrando que han sentido el vivo deseo de vivir sin alcohol y para hacerlo efectivo firmaron el voto: "Por amor a Cristo y de mi patria, hago constar por la presente mi declaración de Independencia del Rey Alcohol".49

Aquí no sólo encontramos la propaganda antialcohólica, sino también parte del discurso que invita a la conversión religiosa. Precisamente, estas palabras emitidas por Maldonado serían retomadas por el converso potencial para estructurar su relato

48 BSTPM, EF, 22-04-1910, p. 251.

49 BSTPM, EF, 09-12-1910, p. 788. 
de conversión al presbiterianismo, puesto que el abandono del alcohol implicaba la posterior dedicación al servicio de Dios, lo cual conllevaría a ser un buen ciudadano.

El medio escrito también fue el método por excelencia para ampliar el mensaje del antialcoholismo, incluyendo folletos para repartir entre la población yucateca, tanto en Mérida como en los pueblos. Esta circulación de folletos se intensificó durante el periodo revolucionario entre 1916 y 1918, en el que las mujeres también tuvieron un papel importante para difundir este mensaje. ${ }^{50}$

Por tanto, las ideas antialcohólicas jugaron un papel importante en las acciones del protestantismo yucateco y campechano, no sólo en el ámbito sociopolítico, sino también en el individualespiritual.

\section{Programa educativo}

En 1907 se estableció el Colegio Pestalozzi, bajo la dirección de la profesora Delia Esparza, meridana graduada de la Escuela Normal Presbiteriana de la ciudad de México, que en su retorno impulsó la creación de dicha escuela para niñas y señoritas. Sin embargo, según los ancianos Mauricio Herrera y Justo P. Cárdenas, su decadencia fue pronta. En gran manera, esta situación se debía a que Esparza ya no fungía como directora desde el mes de marzo de 1910, puesto que al principio contó con 58 alumnos y en el año escolar de 1910-1911 sólo con 9; como en los informes afirman, "este colegio no demuestra progreso", así como que éste se "ha degenerado a gran prisa". El colegio se clausuró a finales de 1911, pero a petición de algunos padres reinicia sus actividades en marzo de 1912 con sólo 5 alumnas; al año siguiente ya contaba con 20 colegialas inscritas. Este colegio, como todos los creados por protestantes, fueron centros

50 Martín, “Experiencias de las asociaciones femeniles”, pp. 182-192. 
patrióticos; el 16 de septiembre de 1912 en los corredores del colegio se organizó una fiesta en honor a la patria y en tributo a sus héroes. ${ }^{51}$

La escuela presbiteriana en Mérida no tuvo gran empuje hasta que la revolución alvaradista llegó a Yucatán. Esta simpatía educativa se dejó ver en los acuerdos tomados en la XXI Reunión Anual del Presbiterio del Golfo realizada en Progreso del 23 al 28 de febrero de 1916, cuando dichos líderes presbiteriales decidieron acudir a la Junta Misionera para que coadyuvase a la creación de la Escuela Normal para niñas y señoritas, la cual estaría (y estuvo) bajo la dirección de la misionera Blanch Bonine.

Una propuesta educativa alternativa no pudo haberse presentado en mejor momento, y es que Alvarado estaba en búsqueda de reformar la educación en el estado; los dos congresos pedagógicos, de septiembre de 1915 y de agosto de 1916, son evidencia de dicha indagación y coyuntura. La educación liberal protestante podía responder a las interrogantes que Alvarado se hizo sobre la consecución de la selección moral y física, así como del amor por la industria y la agricultura por medio de la educación.

La profesora Bonine y el profesor Robert A. Brown, durante sus labores misionales y proselitistas, emprendieron una visita en casi todo Yucatán "tomando nota de los progresos que ofrece la instrucción pública por la acción del gobierno actual”, en el que Bonine y Brown se convencieron "de que una Escuela Normal Presbiteriana en dicha ciudad [Mérida], montada con todos los recursos de la moderna pedagogía, sería un elemento más de luz para las inteligencias". Es muy probable que hayan conocido la mayoría de las escuelas rurales contenidas de un programa laico, las cuales habían sido instauradas por las leyes educativas

${ }^{51}$ BSTPM, EF, 05-05-1911, p. 286; 01-11-1912, p. 686, 695; 15-08-1913, p. 498; diciembre-1935, p. 23. Consúltese MARTín, "Experiencias de las asociaciones femeniles", pp. 191-192. 
expedidas el 21 de julio de 1915, y digo que fue posible porque el "gobernador don Salvador Alvarado los hizo el objeto de delicadas atenciones”. ${ }^{52}$

La relación entre Alvarado y Bonine se volvió muy cordial, hasta el punto que Alvarado comisionó a la profesora-misionera, junto con el secretario de Educación Torres Quintero, para la contratación de maestros en Estados Unidos a finales de 1916. En privado, Alvarado le preguntó a Bonine si la Junta Misionera podría escoger a dichos maestros. La profesora vio en esta situación una oportunidad para influir en la selección de los profesores que estarían laborando en Yucatán. Pero al final, la Junta misionera no autorizó la colaboración económica para el auxilio de los sueldos de dichos profesores. ${ }^{53}$ Este revés retrasó el establecimiento de la escuela deseada.

Para la profesora y los presbiterianos fue difícil encontrar un lugar donde establecer dicha escuela. Alvarado se enteró de esta situación al saber de una solicitud de una manzana de terreno hecha por Bonine, por lo que éste le ofreció la renta de un convento católico confiscado para que la escuela protestante lo ocupase. Bonine le expresó a Alvarado su interés en comprar dicha propiedad; el general respondió que debía conseguir su nacionalidad mexicana para hacer la transacción del inmueble tal como la ley lo requería, pero la misionera rechazó perder su ciudadanía estadounidense. ${ }^{54}$ Fue hasta el mes de julio que se concretaron los planes del Colegio Turner-Hodge, el cual abriría el 2 de septiembre de 1918 en la calle 21, número 102 de Itzimná. El cuerpo docente estuvo conformado por seis profesores, entre ellos tres norteamericanas: Bonine, Bergen y Sage. Los

52 BSTPM, EF, 07-04-1916, p. 251; AGEY, PE, G, vol. 165, exp. 6, 02/06-051916.

53 BALDwin, "Diplomacia cultural”, p. 296.

${ }^{54}$ AGEY, PE, G, vol. 165, exp. 6, 02/06-05-1916. Consúltese McKechnie, “The Mexican Revolution and the national Presbyterian”, p. 167. 
presbiterianos locales anunciaron que para el mes de septiembre “contará esta región con un centro educativo cristiano". 55

De manera expedita, el vicario general envió una circular el 26 de julio de 1918 advirtiendo sobre la próxima apertura del "Colegio Americano" con el fin de prevenir a los sacerdotes de no cometer el error de "aconsejar a los padres de familia pongan allí a sus hijos para que no se hagan solidarios de los daños que en lo futuro pudieran originarse de esta institución". ${ }^{56}$ A pesar de ello, el colegio inició con 63 alumnas, la mayoría provenientes de familias católicas adineradas; incluso, los profesores yucatecos también fueron católicos. Estas condiciones fueron comunicadas como informe a la Junta Misionera con el propósito de exponer la necesidad de establecer una escuela normalista presbiteriana en Yucatán, donde se formara un personal docente protestante, ya que los yucatecos no aceptarían profesores provenientes del centro de México. Y en el mismo sentido revolucionario, propuso crear alguna escuela rural. ${ }^{57}$

Asimismo, la profesora Bonine optó por respetar el programa laico que ordenaba el gobierno con el objeto de apegarse a la reciente constitución estatal de 1918, pero esto le trajo consigo críticas por parte de ciertos misioneros estadounidenses. Sin embargo, el gobierno de Alvarado consideró a la Turner-Hodge como una escuela modelo.

Después del matrimonio de la profesora Bonine en 1919,58 Bergen tomó la dirección del Colegio, el cual seguía un camino positivo ya que cada vez se añadían más asignaturas y matrícula. No obstante, tanto los misioneros como los miembros locales se cuestionaron si esta escuela estaba sirviendo para la causa del mensaje presbiteriano, puesto que no era en definitiva una

\footnotetext{
55 BSTPM, EF, 09-08-1918, p. 510.

${ }^{56}$ AHAY, G, C, c. 45, exp. 2, 26-07-1918.

57 McKechnie, "The Mexican Revolution and the national Presbyterian", pp. 167-168.

${ }_{58}$ BSTPM, EF, 25-04-1919, p. 265.
} 
escuela completamente protestante, considerando el programa educativo laico y su cuerpo docente, en el que se encontraban católicos.

Es así que la escuela evangélica pudo insertarse en Mérida gracias al gobierno de Salvador Alvarado, en gran medida porque durante este periodo revolucionario se buscó renovar la educación y la propuesta protestante ofrecía al menos una alternativa educativa distinta a la que existía en Yucatán.

\section{Prensa}

Durante el porfiriato los presbiterianos de Yucatán no contaron con medios impresos para difundir sus ideales sociales, políticos y religiosos, un elemento que fue inherente al protestantismo mexicano. Fue hasta años posteriores, en la Revolución, cuando apareció en Yucatán la prensa presbiteriana, tal cual fuera un eco que provino desde la capital mexicana. Desde enero de 1913 se publicó el primer periódico presbiteriano yucateco, llamado Fiat Lux; luego, en noviembre de 1915 se divulgó La Luz, y por último La Reforma Social en 1917. En el contenido de estos tres periódicos, los ideales revolucionarios fueron centrales, aun en aquellos artículos que fueron de carácter religioso. Incluso antes de la llegada de Eleuterio Ávila ya se anticipaban los propósitos de la Revolución en la prensa presbiteriana, que pronto instauraría con mayor vehemencia Salvador Alvarado en 1915.

En el núm. 9 del Fiat Lux se encuentran dos artículos que empalman bien el cristianismo protestante con el ideal patriótico, augurando así el sentir de la nueva independencia libre de la dictadura porfiriana. El artículo titulado "Jesús” describe el impacto sociorreligioso que el mesías cristiano tuvo entre la población de su tiempo, desafiando el orden de las escuelas de pensamiento judías como la de los fariseos, saduceos y esenios; la referencia que resalta más es en la que Jesús "contra los escenios [sic] predica la necesidad de salvar al mundo, no retirándose 
de él, sino yendo amorosamente a buscarle en sus enfermedades y en sus errores". Esta perspectiva de la afirmación del mundo y no de su negación permite que Jesús tome una parte activa para transformar las condiciones socioeconómicas, para así imponer una revolución tal como lo haría Alvarado en años ulteriores:

Jesús santifica a todos los débiles, a todos los desgraciados, prometiendo [...] el cielo, a los oprimidos la libertad, a los pobres la posesión de la tierra, a los que han hambre y sed de justicia, el pan de la vida para que satisfagan su hambre, el rocío del bien para que sacien su sed, a los de limpio corazón eterna felicidad, a los pacíficos eterno año, a los perseguidos injustamente un asilo en sus brazos..$^{59}$

Este fragmento cobra sentido al proseguir con el artículo titulado "16 de septiembre" escrito por Ester Labastida, esposa de Lope. En la narración del texto, la gesta heroica de Hidalgo toma una posición similar o igual a la de Jesús, liberando al indio oprimido y subyugado por el dominio colonial. Así también, la muerte de Hidalgo y Jesús fueron comparadas:

Al fin llegó el trágico momento en que en Acatita de Baján, fue traicionado por el Judas Elizondo; el Libertador de México fue hecho prisionero y conducido a Chihuahua; el clero de aquella época se regocijó; las campanas anunciaron regocijo; en las catedrales se cantaron Tedeums; los sacerdotes romanistas vistieron de gala y ante un tribunal afrentaron al Padre de la Patria; el verdugo, sin respetar aquella cabeza cana, la ultrajó en nombre de la religión católica apostólica y romana. ${ }^{60}$

El papel del clero católico en el relato de la independencia llega a ser la personificación de la fusión farisaica y gentil romana,

59 BY, FR, Fiat Lux, 14-09-1913, p. 1.

${ }^{60}$ BY, FR, Fiat Lux, p. 2 [énfasis mío]. 
culpables de la muerte de Hidalgo y de Jesús, respectivamente. Labastida proclama a la memoria de Hidalgo diciéndole, "sellaste con tu sangre" la vida independiente, estableciendo de esta manera una analogía con la sangre de Jesús derramada para la salvación espiritual. Por tanto, en este discurso, la clerecía católica funge como el enemigo de la Patria, y a su lado la embriaguez, la cual se consideró como un "caballo de Troya" para la sociedad yucateca pues "sus peores enemigos son, el 'Xtabentún', el vino, la cerveza y todas las bebidas embriagantes con que los mexicanos se envenenan". ${ }^{61}$

La Iglesia católica, como enemiga de la patria, tenía que ser desenmascarada ante la sociedad yucateca. Por tanto, la prensa presbiteriana atacó dos elementos esenciales del catolicismo: la misa y el confesionario. La misa fue concebida como una invención medieval supersticiosa del clero romano tomada del paganismo; es decir, contraria al cristianismo puro que predicó Jesús, y que por ende deja de ser una institución divina. Es así que el periódico $L a L u z$ aconseja a aquellos padres que quieran "el mejoramiento de sus hijos, deben enseñarles que la mejor misa, es la misa del trabajo, de la instrucción y de la austeridad; si así hicieren, formarán ciudadanos útiles a la tierra que los vio nacer". ${ }^{62}$

El primero de marzo de 1914, antes de la llegada de Eleuterio Ávila, Fiat Lux publicó el artículo "La confesión auricular, sinónimo de inmoralidad”. El título por sí mismo expresa las ideas pertenecientes a la campaña anticlerical desarrollada durante el constitucionalismo, en el que muchos de los líderes políticos carrancistas implementaron medidas similares contra la confesión como uno de los ejes centrales de las reformas, y que en Yucatán sólo se concretizó con la llegada de Alvarado. ${ }^{63}$ Fiat Lux

${ }^{61}$ BY, FR, La Reforma Social, 08-09-1917, p. 3.

62 BY, FR, La Luz, 21-11-1915, p. 3.

63 Fallaw, "The seduction of Revolution". 
dice: "la propaganda papal es atraer a sí a la mujer, ligándola de modo que no se le escape por medio del confesionario". Estas ideas no sólo se vinculan con la posible inmoralidad, sino también con que la mujer como fiel devota representa la fortaleza de toda institución religiosa. Prosigue el articulista: "los esposos, por propia dignidad deberían ser los primeros en apartar a sus consortes de esa inmoralidad y los padres por el honor de sus hijas no deberían permitir bajo ningún concepto que ellas sean pervertidas y arruinadas por el clero" ${ }^{64}$

Empero, los presbiterianos buscaron convencer de que la Revolución no tendría efecto si no se realizaba también una reforma en la moral de los individuos, ${ }^{65}$ puesto que "no debe olvidarse que la Revolución no sólo es 'Justicia', sino q'es también 'moralidad'”. ${ }^{66}$ Esta idea se hace más explícita en un artículo publicado en La Reforma Social el 8 de septiembre de 1917:

No hay reforma posible en las costumbres cuando la fuente de la vida está maleada y es la que necesita la reforma [...].

[...] La Ley, para que tenga fuerza, ha de estar respaldada por autoridad competente, de otra manera será pisoteada cada vez que el individuo no se sienta dispuesto a cumplirla [...]. Dios, la eternidad, el juicio final son cosas tan lejanas (por más que no lo sean) que se esfuman en el horizonte sin hacer ninguna presión sobre la conciencia.

Por una parte se necesita una creencia más positiva en un Dios soberano que todo lo ve, que lo sabe todo, que lo escribe todo para juzgar más tarde a los hombres según sus obras. Pero estas creencias

${ }_{64}$ BY, FR, Fiat Lux, 01-03-1914, p. 1.

${ }^{65}$ Esta idea resonó evidentemente en el "Grito de Guadalajara” proclamado por Plutarco E. Calles el 20 de julio de 1934, cuando dijo que la revolución no había terminado y que era necesario entrar al "periodo revolucionario psicológico"; es decir, de las conciencias. Alvear, La Iglesia en la historia, pp. 294-295.

${ }_{66}$ BY, FR, La Luz, 21-11-1915, p. 1. 
no han de ser una teoría o especulación, han de ser un hecho de conciencia, que el individuo la sienta de día y de noche, sólo o acompañado, en la ciudad o en el campo, y que tiemble ante la idea de sus responsabilidades. Y a este temor sería un freno que en muchos casos contendría al delincuente, pero que no le ayudaría del todo a ejecutar el bien y a resistir las tentaciones que parece irresistibles. [...]. Entonces, pues, nuestra enseñanza y nuestro esfuerzo han de tender hacia una reforma espiritual si queremos la reforma social. ${ }^{67}$

Entonces, si la conquista católica vino a ser la base del dominio político y militar de España sobre la tierra azteca, la revolución buscada por el gobierno alvaradista también tenía que fundarse en una revolución moral-espiritual, y el protestantismo era la opción más adecuada para vencer la superstición del catolicismo y la embriaguez que frenaba el avance hacia una sociedad industriosa como la de Estados Unidos de América, la de Suiza y la de Escocia.

\section{LA MARGINALIDAD POLÍTICA DEL PRESBITERIANISMO \\ EN EL GOBIERNO ALVARADISTA}

A pesar de que el protestantismo en Yucatán traía consigo las ideas revolucionarias antes de la llegada de Ávila y de Alvarado, éstas sólo tuvieron eco entre un sector limitado de la población meridana. Los ideales maderistas compartidos por los protestantes mexicanos no lograron modificar el aspecto político y económico de Yucatán, el cual se mantenía indisoluble desde los años del porfiriato. Por un lado, la clase gobernante y los hacendados oligarcas mantenían un estrecho vínculo económico; por el otro, el clero se había recuperado del peoncismo gracias a la alianza que entabló con el gobierno de Olegario Molina. ${ }^{68}$

67 BY, FR, La Reforma Social, 08-09-1917, pp. 1, 4.

68 MenÉndez, Iglesia y poder, pp. 174-177. 
El clero inició una nueva etapa bajo el mando de Martín Tritschler, un obispo que era parte del amplio proceso de romanización del catolicismo en México; ${ }^{69}$ por tanto Tritschler poseía ventajas como obispo, y esto se reflejó en 1907, cuando fue aceptada la erección de la arquidiócesis de Yucatán. Esta posición privilegiada de la Iglesia frente al gobierno molinista permitió que dicha alianza emprendiera un proyecto de modernización progresista a través de la instrucción pública y del control de un programa de transición de la religiosidad popular hacia una formal. En términos generales, el fin fue conformar y promover una identidad yucateca por medio de la religión católica, con el objeto de pacificar aquellos remanentes de las zonas rebeldes nacidas de la Guerra de Castas. Con estas condiciones, la Revolución tenía que llegar desde afuera y Salvador Alvarado sería su emisario. ${ }^{70}$

Está claro que los presbiterianos tuvieron pocas oportunidades de influir en las políticas públicas de Yucatán durante estos primeros lustros del siglo xx; por tanto, las noticias que les llegaban desde México resultaban esperanzadoras. El constitucionalismo carrancista estaba entregando puestos públicos importantes a los protestantes; ésta era una oportunidad evidente para los presbiterianos yucatecos que tenían como referencia principal a los hermanos Sáenz.

${ }^{69}$ La romanización es entendida como la "reforma eclesiástica del Vaticano que se caracterizó por la paulatina centralización de las iglesias tendiente a fortalecer la autoridad de la jerarquía romana y del papado frente al poder que ejercía el clero local". El Colegio Pío Latino Americano fue una de las estrategias para acercar a los estudiantes de dicho colegio con profesores de la Universidad Gregoriana vinculada con el papado. En México, el arzobispo Labastida coadyuvó a que los egresados del Colegio Pío engrosaran el cuerpo eclesiástico desde finales del siglo XIX, entre ellos Martín Tritschler Y Córdova; por tanto, la designación de Tritschler como obispo de Yucatán en 1900 responde a este proceso de centralización eclesiástica. BAUTisTA, "Hacia la romanización”, pp. 100, 109-111, 136-138.

70 Joseph, Revolución desde afuera, pp. 27-30; SAVARINo, Pueblos y nacionalismo, pp. 189-215; BAUTISTA, "Hacia la romanización”. 
Los destellos del constitucionalismo en Yucatán se vislumbraron con la llegada de Eleuterio Ávila en 1914, quien desde el 13 de noviembre promulgó medidas anticlericales, como la prohibición de la vestimenta del hábito en lugares públicos, la comunicación entre iglesias y casas curales, la restricción de algunas prácticas católicas por antihigiénicas como el beso a las imágenes, el transporte de cadáveres a la iglesia y el uso del agua bendita. Anticipándose a estas medidas, Martín Tritschler zarpó hacia La Habana el 4 de octubre de 1914, y con él casi la mitad de los sacerdotes que eran de origen español. Pero Ávila flaqueó y fue sustituido por Toribio de los Santos, quien también perdió frente al movimiento argumedista. ${ }^{71}$

Por tanto, Carranza mandó al general Alvarado para recuperar el control, y éste, destruyendo a todas las tropas argumedistas desde su entrada a territorio yucateco tomó la gubernatura en marzo de 1915, siendo más severo contra el clero. Para el general, la Iglesia católica representaba una extensión de la oligarquía yucateca, la cual entenebrecía a la población con sus supersticiones. Por este motivo, creía necesaria la reforma de la educación, que se encontraba en manos del clero, así como la desestructuración de su poder económico, que residía en sus propiedades inmuebles.

Inicialmente, las escuelas católicas fueron cerradas para convertirlas en escuelas públicas y laicas, verbigracia el Colegio Ildefonso y el Colegio Josefina. Las iglesias y parroquias todavía se mantuvieron abiertas hasta la orden de clausura que se emitió en septiembre de 1915. Pero dado el conocimiento que poseían los presbiterianos sobre las acciones constitucionalistas, se anticiparon solicitando en mayo de 1915 que les fuera dado el templo de la Compañía de Jesús (Tercera Orden) o el templo de San Juan para "consagrarlo a los servicios cristianos del culto Evangélico", arguyendo que la iglesia católica tenía más

71 Chacón, "Salvador Alvarado and the Roman Catholic", pp. 249-251. 
templos de los que necesitaba para sus cultos; sin embargo, los alvaradistas respondieron que todavía no resolvían "el problema de las Iglesias”. ${ }^{72}$ Empero, en diciembre de 1915 la iglesia de la Tercera Orden fue cedida al Círculo de Estudiantes y no a los presbiterianos, y en 1917 fue destinada como sala de sesiones del Congreso del estado; la iglesia de Jesús María fue entregada a los masones el 14 de diciembre del mismo año, y ésta fue inaugurada oficialmente como templo masón en el año de $1918 .^{73}$

En este punto es necesario detenernos para referir un hecho que reflejó el distanciamiento entre la visión revolucionaria del presbiterianismo y la de la Liga de Estudiantes. José D. Ramírez Garrido pronunció un discurso el 15 de enero de 1916 en el extemplo de la Tercera Orden, en el que arremetió contra la interpretación de la figura de Jesús como socialista. Evidentemente, esta noción formaba parte del discurso plasmado en la prensa presbiteriana y que justificaba su apoyo a las reformas que vendrían con Salvador Alvarado. La conferencia de Ramírez Garrido tuvo por objeto "quitarle [a Jesús] la falsa aureola de moralista y socialista”, con la que "lo han adornado con ligereza suma los oradores y poetas chirles" ${ }^{74}$

Continuando, el siguiente golpe alvaradista fue contra toda la ornamentación y artefactos que se encontraban dentro de las iglesias. El 20 de enero de 1916, Alvarado "dispuso que todas las alhajas de las iglesias, se depositasen en las Comandancias Militares". El clero y algunos hacendados aliados a la iglesia protestaron contra este acto calificado como sacrílego, e interpusieron demandas contra Alvarado y sus comandantes militares.

Martín Tritschler con angustia recibía en La Habana las noticias por medio de las cartas escritas por algún cura o hacendado, y en su impotencia por no poder ejercer una defensa directa,

72 AGEY, PE, G, vol. 51, exp. 33, 15-05-1915.

73 AHAY, G, C, c. 64, exp. 3; c. 66, exp. 5, f. 507.

74 Ramírez, “Jesús ante la moral...”, p. 10. 
escribió una carta a Carranza el 21 de febrero de 1916, acusando a Alvarado como instigador de los "atropellos de que era víctima en Yucatán el clero católico” y solicitando medidas para el cese de estos actos. Pero Carranza nunca respondió y Tritschler intentó más de una vez reenviar dichas misivas sin tener distinta suerte. ${ }^{75}$ Alvarado tenía el poder y evadió fácilmente estas acusaciones.

El hecho anticlerical e iconoclasta más significativo del periodo alvaradista fue la destrucción del interior de la catedral como parte de una manifestación de obreros el 14 de septiembre de 1915, en el que al final todos gritaron en favor del general Alvarado y al mismo tiempo "mueras” a los curas. Esta movilización fue liderada por Diego Rendón, intelectual obrerista y masón, quien tuvo la palabra para iniciar el acto. Y este tipo de ataques iconoclastas se repitieron el 1o de mayo de 1916, cuando la organización de la Casa del Obrero Mundial destruyó varias iglesias de Mérida, hecho en el que se perdieron los ornamentos religiosos.

Aquí cabe resaltar que los presbiterianos veían con buenos ojos a esta organización obrera, en cuanto formaban parte del bloque revolucionario. Los miembros protestantes fueron colaboradores del gobierno alvaradista y por ende existía una simpatía por estas organizaciones. Y en tanto colaboradores, algunos presbiterianos lograron obtener ciertos beneficios laborales y contados puestos políticos, como Aurelio Maldonado, anciano de la congregación de Progreso, que durante el gobierno de Alvarado pasó de cargador del muelle a oficial de aduana del puerto; ${ }^{76}$ otros dos obreros presbiterianos lograron colocarse en puestos clave en el Departamento de Tesorería, aunque esto no hubiera sido posible sin la ayuda del secretario privado de

75 AHAY, G, C, c. 66, exp. 5, f. 520.

76 BSTPM, EF, 04-04-1913, p. 197. 
Alvarado, Pablo Garza Leal, hijo del ministro presbiteriano Leandro Garza. ${ }^{77}$

Aun así, los masones fueron los que tomaron una parte más activa en el proyecto revolucionario al amparo de Alvarado, quien le subsidió la sindicalización de los masones con la cantidad de 20000 pesos; y no está de más decir que el periódico masón Nigromante apareció por primera vez en 1916 y la revista El Partenón en 1918, de la logia La Oriental. Los miembros de las logias tenían una larga data en participación política en Yucatán, mucho más que la de los protestantes, que iniciaron un par de años antes del alvaradismo. La prolongada experiencia de los masones fue evidente en 1918, cuando se inauguró el templo masónico en la antes iglesia de Jesús María, pues reunió a intelectuales que habían participado en la creación de la Unión Obrera de Ferrocarrileros en 1911 y en la conformación del Partido Socialista Obrero de 1916. La masonería en Yucatán entabló un vínculo notorio con los grupos obreros, en el que los primeros fueron sus dirigentes. De esta manera pudieron poseer redes clientelares que les permitieron disputar puestos públicos por medio del partido socialista, como Víctor Rendón, que fue secretario general de Gobierno durante la gestión de Alvarado, y Eladio Domínguez, jefe del Departamento del Trabajo desde 1918. ${ }^{78}$

Pero la importancia de la participación de los masones y protestantes no sólo radicó en su dirigencia, sino en la propaganda desfanatizadora y anticlericalismo que desperdigaban en medio del público urbano y en los pueblos. Precisamente, la

77 McKechnie, “The Mexican Revolution and the national Presbyterian”, p. 126. Posteriormente, Pablo Garza se matrimonió con la hija de Álvaro Torre Díaz, que en el momento en que éste ascendió a la gubernatura lo nombró jefe de la policía de Yucatán. Agradezco a Ben Fallaw la comunicación de este dato importante.

78 Joseph, Revolución desde afuera, p. 137; BALAM, La masonería en Yucatán, pp.13-15; DíAz, "El arte monumental”, p. 123. 
combinación del credo revolucionario y del protestante-masón les confería a los discursos un tufo más de anticatolicidad que de anticlerical; y esta contraposición no se limitó sólo a la manifestación oficial del catolicismo, sino también a la popular que se concretizaba en los pueblos.

Para cumplir este cometido, Alvarado creó el Departamento de Información y Propaganda en 1915, el cual tuvo el propósito de enviar agentes a diferentes zonas del estado para recoger información, anunciar la Revolución y cumplimentar las disposiciones gubernamentales. ${ }^{79} \mathrm{El}$ agente propagandista más conocido fue Santiago Pacheco Cruz; la popularidad de este personaje en la historia revolucionaria se debe más a la publicación de su libro Cartas desfanatizadoras, por lo que se ha oscurecido la agencia del quien fuera jefe de dicho departamento de propaganda entre 1916-1917, el ministro Plácido Lope. Cabe mencionar que este ministro, presidente del Presbiterio del Golfo, realizó “labores desfanatizadoras” desde 1915; así también, en 1918 fungió como inspector del Partido de Mérida y jefe de la institución Bolsa de Trabajo a mediados de 1919.80

Con el puesto ocupado por un líder presbiteriano, le aseguraba a Alvarado la suficiencia de personal para esta labor de propaganda revolucionaria. En los informes que Lope envió al gobernador, señala a los presbiterianos como "correligionarios” de la labor propagandística. Y para garantizar dicho respaldo del gobierno a sus labores evangélicas, informaba sobre las opiniones favorables de las mujeres presbiterianas respecto a las políticas económicas de Alvarado y sobre la disposición de los varones para el apoyo en la milicia revolucionaria.

A mediados de 1916, Lope se dirigió a la zona oriental para cumplir con sus labores desfanatizadoras visitando Valladolid, Ebtún, Cuncunul, Dzitnup y Chichimilá; en este último pueblo

79 Savarino, Pueblos y nacionalismo, p. 342.

80 Koyock, "Sin abrigo ni pan", p. 63. 
sostuvo dos reuniones a finales del mes de agosto. Lope refiere que durante sus exposiciones fue constantemente interrumpido por las intervenciones de los pobladores, la mayoría relacionadas a la devolución de los santos o a las preguntas de: “ ¿Cuándo vuelven los tata-curas?' ‘QQué haremos con nuestros hijos que no hay quien los bautice?' 'No queremos que queden sin bautizar'. 'Queremos que el señor Gobierno deje que haya fiestas con sus corridas de toros'. (En lengua maya me hacían las preguntas)". La respuesta de Lope, como discurso, transitó de lo revolucionario a lo protestante.

Plácido les pedía que no se preocupasen por los ídolos, pues no tenían vida ni poder para hacer el bien o el mal. Hacía referencia explícita sobre la quema de ídolos a manos del gobierno y de los obreros, sin que éstos hayan sufrido alguna desgracia por realizar semejante acto. Esto servía de evidencia de que los santos eran "instrumentos en las manos de los 'curas' para explotar la fe religiosa" de los campesinos y trabajadores. De pronto, otro poblador levantó la voz y dijo: "Esta bien, pero estamos acostumbrados con ellos", refiriéndose a los curas y a los santos. La respuesta de Lope se dirigió a la necesidad de preservación de los hijos, quienes tienen el derecho de decidir si seguir o no bajo el yugo católico mediante el bautizo. Lope señaló el bautizo y las fiestas con corridas de toros como medios principales para enriquecer a los curas y a los notables del pueblo, los cuales normalmente están vinculados con la iglesia. Y es precisamente en este punto de su discurso que transita al mensaje protestante como sigue:

Quiero que también entiendan que el Gobierno no es enemigo de la religión cristiana, lo único que procura evitar, es que se explote el trabajo de los pobres a nombre de la religión.

Cada quien, puede ser o no religioso, Uds. pueden serlo si quieren. Si desean serlo realmente, yo les diré cómo serlo sin ser idólatras ni fanáticos. Piensen Uds. en Jesucristo y procuren imitarlo 
en todo lo que les sea posible. Él cuando niño asistió a la escuela de su pueblo y aprendió a leer, como hijo fue siempre obediente a sus padres, fue fiel amigo, hizo todo el bien que pudo, como ciudadano pagó su contribución personal, como artesano fue cumplido pues fue carpintero.- amó el trabajo.

Así Uds. manden a sus hijos a la escuela, sean buenos amigos, no hagan mal a nadie y sí todo el bien que puedan, amen el trabajo, paguen fielmente sus contribuciones, a fin de que haya todo lo necesario para el mejoramiento del pueblo de Uds. ${ }^{81}$

Es evidente que para Lope era importante recalcar que la figura de Jesucristo es el modelo ideal del ciudadano de la Revolución, en el sentido de que era buen obrero sin fanatismo, tal como deseaba el gobierno alvaradista. En el discurso de Lope se puede encontrar lo que su prensa comunicaba: la necesidad del credo protestante como base esencial de la revolución.

Tal vez, la labor de agente de propaganda fue utilizada por Lope como un medio efectivo para difundir el mensaje protestante con mayor amplitud. La experiencia de sus homólogos presbiterianos de la ciudad de México le dictaba las acciones necesarias para llevar a cabo la misión divina, como la de aprovechar la coyuntura revolucionaria-constitucionalista. Esta hipótesis puede confirmarse con las dos últimas solicitudes que le presentó al gobernador.

La segunda solicitud fue un proyecto para establecer un centro de reunión social que se denominaría "La Casa del Pueblo", a la que las personas de "todas las clases sociales sin distinción de alcurnia, credos políticos ni religiosos” pudieran asistir. El objetivo principal era "formar hombres completos, esto es, hombres prácticos, hombres de carácter y hombres de moralidad, en una palabra, que sean útiles a la Patria”. Para eso ideó múltiples departamentos vinculados a la educación física,

81 AGEY, PE, G, vol. 198, exp. 36, 08-09-1916. 
artística y cultural, así como la estructura organizacional que dirigiría esta Casa. Pero tal vez, por las siguientes palabras de Lope, el gobernador titubeó en su apoyo directo:

Señor General, para fundar la "Casa del Pueblo" se necesitan $\$ 3000$ TRES MIL PESOS, para comprar los útiles más indispensables, y para el sostenimiento de la misma, se necesitan $\$ 1500$ [...] Pero de una manera especial, suplico a Ud. me dé arrendadas, las casas 517 de la calle 67 y 532 de la calle 64; ambas casas, pertenecen al templo llamado de la Candelaria, y por lo tanto son del Estado, y están actualmente ocupadas por particulares; me he fijado en ellas, porque la primera tiene salones amplios y patio muy grande propios para reuniones y juegos deportivos, y la segunda propia para la Escuela Nocturna. Si ordena Ud. que me la cedan para "La Casa del Pueblo" se lesionarán, es verdad, dos familias, pero en cambio se beneficiarán centenares de familias. ${ }^{82}$

La respuesta de Alvarado no fue alentadora, les comunicó a los presbiterianos que la idea de dicho proyecto sólo "pueden llevarla a la práctica" las sociedades obreras, con las que debería exponer su plan. Tal vez sí fue presentada ante las organizaciones obreras pero sin haberle dado importancia inmediata, por lo que es posible que posteriormente haya sido cooptada la idea durante el socialismo posrevolucionario para construir la sede del Partido Socialista del Sureste, inaugurada en 1928; es decir, 12 años después. ${ }^{83}$

82 AGEY, PE, G, vol. 206, exp. 2, 10-10-1916.

83 Esta evidencia demuestra que la inspiración de Álvaro Torre Díaz planteada en diciembre de 1925 provino de este proyecto propuesto por el pastor presbiteriano en 1916, el cual se había ignorado y por ende archivado en los papeles del partido socialista. Los deseos expuestos por Torre Díaz son claros al respecto: "Me esforcé en hacer comprender a las Ligas [de resistencia] que su principal acción es la societaria, pues la política sólo la deben ejercer incidentalmente [...]. Que, por tanto, todos sus afanes deben dedicarlos a procurar el mejoramiento no tan sólo material, sino, sobre todo, el espiritual de sus 
La última y tercera tentativa tampoco tuvo destino positivo. P. Lope, como presidente del Comité de Evangelización de Yucatán, procedió a realizar la solicitud en abril de 1917, en la que pidieron que les fueran concedidas la Iglesia Candelaria, la Ermita y la Santa Lucía “para la propaganda evangélica”. De nuevo, la respuesta fue negativa arguyendo que era necesario esperar el régimen constitucional. ${ }^{84}$

Sin embargo, Lope se mantuvo dentro del gobierno revolucionario. Alvarado lo nombró visitador de oficinas del Registro Civil a mediados de $1917 ;^{85}$ este puesto no le fue ajeno al ministro, pues un mes antes de la toma de la gubernatura por Alvarado fue nombrado oficial del Registro Civil de Caucel. ${ }^{86}$ Este dato es sugerente, puesto que significa que Plácido simpatizó parcialmente con el gobierno de Argumedo, para luego convertirse en jefe propagandista revolucionario. Claramente, estas acciones respondían a una estrategia de acomodación política, muy recurrentes en el presbiterianismo.

Tal vez, el posible conocimiento de estos cambios políticos por parte de algunos miembros presbiterianos no terminaba por convencer a algunas facciones revolucionarias. En el periódico La Voz de la Revolución, con el cambio en su dirección, publicó a mediados de 1917 un artículo contra el protestantismo,

\footnotetext{
coasociados, fundando escuela en el seno de las mismas, organizando fiestas culturales y deportivas, etc.”. También la siguiente cita: “[...] dicho edificio tendrá un casino para obreros, en el que habrá juegos de billar y otros lícitos, con exclusión absoluta de cualesquiera carteados; campo de deportes, de gimnasio, un consultorio gratuito; dormitorio gratuito destinado a los ligados del interior del Estado, en el que podrán descansar, un comedor; un campo de experimentación agrícola y una biblioteca". DíAz, "El arte monumental”, pp. 210-211. Es evidente que Torre realizó algunas modificaciones y adecuaciones al proyecto, pero es claro que el plan protestante fue cooptado.

${ }^{84}$ AGEY, PE, G, vol. 260, exp. 28, 18/21-04-1917.

${ }^{85}$ BY, FR, La Reforma Social, 01-09-1917, p. 2.

86 BY, FR, Diario oficial del gobierno del estado libre y soberano de Yucatán, 26-02-1915, p. 582.
} 
manifestando la añeja acusación de ser enemigo de la patria y divisor de la unidad nacional. Los presbiterianos no esperaban una crítica proveniente de una fuente oficial revolucionaria con la cual habían colaborado, por lo que expresaron su desencanto con dicho periódico por medio de El Faro y La Reforma Social señalando el posible vínculo entre los católicos y el nuevo director del periódico. ${ }^{87}$ En estos ataques escritos se cuestionó a Lope y a Liborio Blanco de Muna por su participación política siendo agentes religiosos, lo cual mereció las réplicas de ambos. Esto demuestra que a finales de 1917 el partido alvaradista ya no era homogéneo; no todos coincidían con la colaboración del protestantismo, el cual no dejaba de ser una religión como la católica, por lo que las facciones más radicales buscaron desplazar completamente el factor religioso en el programa revolucionario.

Estos cambios dentro del régimen revolucionario podrían explicar los rechazos de las tres peticiones de los presbiterianos. Durante el alvaradismo, el presbiterianismo tuvo menor influencia que sus homólogos en el centro del país, siendo más beneficiados los masones. Aunque Lope supo utilizar su puesto de agente propagandista a conveniencia de la misión religiosa con el fin de conseguir simpatizantes presbiterianos; es decir, la revolución financió y Lope buscó que se le financiaran sus labores misioneras en los pueblos de Yucatán, a juzgar por las palabras de su informe:

Respecto de la propaganda, sigo en la zona oriental del estado, aunque por hoy no se puede apreciar el resultado, sin embargo, está germinando la obra. Respecto de Valladolid, se está avanzando, porque aunque no tenemos local adecuado para las reuniones, tengo

87 BY, FR, La Reforma Social, 01-09-1917, p. 1; BSTPM, EF, 02-10-1917, pp. 644-645. 
en mi lista a varias familias que han salido ya de la idolatría, y que siguen propagando entre los suyos. ${ }^{88}$

La Constitución de 1918 marcó el final del periodo alvaradista y al mismo tiempo la culminación de su proyecto político, y los presbiterianos no lograron ver más beneficios que el permiso de la permanencia de la escuela Turner-Hodge. En términos generales, la ley sobre la educación fue la más representativa, pues propugnó por una educación obligatoria, laica y combativa al fanatismo, así como la imposibilidad de ser electo si se era ministro religioso. En la visión de Savarino, la constitución tenía una alta influencia jacobina y masónica, ${ }^{89}$ aunque sólo era explícita en la ley educativa. Empero, los gobiernos socialistas supieron manejar a modo lo que implicaba la idea del combate al fanatismo; es decir, sus acciones se centraron en lo que ellos definían como fanático. Y precisamente esto preocupó a Tritschler, pues se habían concretado políticas desfavorables hacia la iglesia debido a la lenidad en la práctica, en la que según el arzobispo no recibían ni siquiera "como una limosna precaria los actos de tolerancia” que también merecía el clero católico. ${ }^{90}$

No obstante, con la retirada de Salvador Alvarado los miembros con mejor posición en el partido socialista tomaron el timón de la administración, como Álvaro Torre Díaz, Carlos Castro Morales y Felipe Carrillo Puerto. Los dos primeros serían más blandos con el clero, entablando negociaciones políticas y estableciendo ciertas prerrogativas.

88 AGEY, PE, G, vol. 198, exp. 36, 08-09-1916 [énfasis mío].

89 SAvarino, Pueblos y nacionalismo, pp. 341-342.

90 AHAY, G, C, c. 72, exp. 7, f. 205, 01-04-1918. 
EL PROGRAMA PRESBITERIANO-REVOLUCIONARIO FUERA DE MÉRIDA

Al exterior de Mérida también se gestaron grupos presbiterianos que actuaron en el círculo revolucionario; principalmente fueron lugares con características urbanas, como Ticul, Muna y Progreso. Como veremos, el perfil liberal, patriótico y revolucionario en dichos lugares no fue fortuito.

La congregación de Ticul fue inaugurada por el pastor Alfonso Herrera en 1902; pero fue hasta la llegada de Plácido Lope, en 1907, cuando se impulsó el involucramiento público y político de la congregación. Esta dirección fue reforzada con el retorno de los conversos ticuleños Asunción Blanco y Ciriaco Cauich, después de que ambos se trasladaran en 1903 a la ciudad de México para realizar sus estudios en el Seminario Teológico de Coyoacán. En efecto, ambos trajeron consigo las ideas nacionalistas y revolucionarias de los presbiterianos constitucionalistas del centro del país. En consecuencia, el rastro de esta línea de pensamiento presbiteriano se siguió en los lugares donde Ciriaco y Asunción llegaron a liderar. A finales de 1909, Ciriaco fue designado encargado de la congregación de Ticul, Asunción Blanco de la de Progreso y Liborio Blanco pasó a erigir una congregación en Muna. ${ }^{91}$

Ticul consiguió erigir una escuela en 1907 con el nombre de "Benito Juárez", encargándose de ella una estudiante de la Escuela Normal Presbiteriana de San Ángel a finales de 1911. Celebraron fiestas cívicas y patrióticas incluyendo al medio público y político. En 1913 participaron en una velada de temperancia junto con la sociedad local, y así fueron abriéndose camino hacia su visibilización pública. ${ }^{92}$

${ }_{91}$ BSTPM, $E F, 01-05-1908$, p. 72; BSTPM, EF, 14-05-1909, p. 274; BSTPM, $E F, 12-11-1909$, p. 722.

${ }_{92}$ BSTPM, EF, 26-13-1913, pp. 808-809. 
El gran pueblo de Ticul era liberal, pinista-maderista y posteriormente revolucionario; los presbiterianos locales también así lo fueron. Esto les granjeó la accesibilidad a la política local. Verbigracia, Ciriaco Cauich fue vicesecretario de la Junta Patriótica en 1912, supervisor de la casilla núm. 2 en las elecciones municipales de 1916, presidente de la Liga de Resistencia en 1917 y oficial de Registro Civil en 1918.

Las condiciones fueron favorables para los presbiterianos durante el periodo alvaradista; incluso, ellos fueron los únicos a quienes se les devolvió la campana que Alvarado había mandado expropiar a todo grupo religioso; esta gestión fue posible por que el mayor Santiago Barbosa era exalumno del colegio presbiteriano de Coyoacán. ${ }^{93}$ De este modo los protestantes fueron involucrándose en la política revolucionaria del pueblo, aunque la mayoría de los líderes revolucionarios de Ticul seguían perteneciendo a la clase hacendaria. ${ }^{94}$

No obstante, en 1919, con los cambios políticos a nivel estatal con el zamarripazo, los católicos opositores al gobierno de ese momento aprovecharon para realizar ataques contra los protestantes de Ticul, quienes estaban vinculados con el socialismo. Frente al templo presbiteriano se dinamitó una bomba en diciembre de dicho año, que destruyó los archivos e inmuebles, lográndose reconstruir el templo hasta 1923. ${ }^{95}$

Es así que los presbiterianos de Ticul pudieron colocarse junto a los notables de manera muy fácil, debido a que los primeros protestantes, como los Blanco Castillo y Blanco Rosado, provenían de las familias mestizas notables - aunque no todos sus miembros pertenecían a esta clase social-. Sin embargo, los líderes sí, incluso Ciriaco Cauich, con apellido maya, no era campesino sino peluquero de oficio.

${ }^{93}$ Blanco, Breve reseña histórica, p. 14.

${ }^{94}$ Savarino, Pueblos y nacionalismo, pp. 249, 347, 349, 366.

95 Blanco, Reseña histórica, p. 15. 
En otro tenor, la permanencia del grupo presbiteriano fue garantizada por su posición política liberal y revolucionaria, la cual fue acorde a la sociedad ticuleña. Y esta misma ruta fue seguida por los grupos de Muna y Progreso. Esta última es la tercera congregación más longeva de Yucatán. Desde 1906 habían iniciado la construcción de su primer templo con el nombre "Jesús". La ciudad porteña aglutinó a centenares de familias comerciantes por la obvia razón de ser el polo de comercialización de exportación de todo el estado de Yucatán; por tanto, era una ciudad con poca población indígena. El presbiterianismo logró fincarse con facilidad en una sociedad comercial y mercantil como la del puerto; entre sus miembros aparecieron personas con apellido Maldonado, Rendón y Arjona. Dada la posición de dichos miembros, la congregación avanzó con rapidez en términos organizativos; incluso en 1907 ya tenían una escuela evangélica atendida por Julia Rendón, a la que asistían niños católicos a quienes se les enseñó “a ser buenos con Cristo. De esta manera los enseña a ser cristianos". ${ }^{96}$

Igualmente, en 1910 organizaron campañas antialcohólicas y también la línea patriótica fue emulada por esta congregación. En 1912, en el marco de la Convención Regional de Escuelas Dominicales, los presbiterianos de la región del Golfo visitaron el puerto de Progreso; éstos fueron recibidos por los miembros locales y dirigidos al parque Jardín Juárez "con el fin de realizar una manifestación al Benemérito de las Américas y autor de nuestras Leyes de Reforma". Las mujeres ofrecieron flores al monumento de Juárez y recitaron poesías en honor al valor patriótico. Posteriormente se realizó un desfile, combinando el estandarte de la nación mexicana y el de la iglesia presbiteriana, en el que cruzaron por la plaza principal de Progreso, donde se encontraba el monumento a Miguel Hidalgo, al que también se le elogió. ${ }^{97}$

\footnotetext{
96 BSTPM, EF, 01-09-1907, p. 136.

97 BSTPM, EF, 01-11-1912, p. 696.
} 
El 19 de julio de 1913, Plácido Lope designó a Estanislao Llera como líder de la congregación, sin ser de Yucatán. El liderazgo de éste fue muy significativo para la congregación porteña, sobre todo cuando llegaron los años de la revolución. Estanislao Llera aparece desde principios de 1916 como inspector de pesas y medidas del mercado público; este puesto le concedió ampliar sus interacciones sociales con los pequeños comerciantes y consumidores que provenían de los lugares aledaños. Los puestos públicos en este periodo eran otorgados a aquellos que declaraban lealtad al gobierno revolucionario, y Llera lo manifestó frente a sus detractores, que fueron comerciantes locales, diciendo que él era "admirador y amigo de la Revolución desde el año de 1910 que la proclamó el Señor Madero". ${ }^{98}$ Esta referencia tenía un significado importante, pues implicaba ser revolucionario en Yucatán mucho antes de la llegada de Ávila y Alvarado, conocidos como los primeros emisarios de la revolución mexicana. Las quejas de sus acusadores sobre sus arbitrariedades en el mercado local nunca fueron admitidas por el gobierno. ${ }^{99}$ Las facilidades del gobierno revolucionario hacia la congregación de Progreso fueron evidentes, e incluso pudo realizarse la XXI reunión presbiterial en dicho puerto en 1916, año álgido del alvaradismo. ${ }^{100}$

En el caso de Muna, la empresa evangelística fue iniciada por Plácido Lope en 1907. El carácter liberal y pro-pinista de la población ofrecía una oportunidad al presbiterianismo. Lope consiguió congregar a un número de personas interesadas en el protestantismo desde marzo de 1908. Para finales de este mismo año se contabilizó sólo a dos miembros en plena comunión y 80 adherentes. ${ }^{101}$ A mediados de 1909 Liborio Blanco se mudó a

\footnotetext{
98 AGEY, $P E, A$, v. 139 , e. $65,11-02-1916$.

99 AGEY, $P E, A$, v. 148 , e. 65, 21-03-1916.

100 BSTPM, $E F, 07-04-1916$, p. 229; BSTPM, EF, 17-04-1916, pp. 249-251.

101 BSTPM, $E F$, 15-07-1907, p. 112; BSTPM, $E F, 22-01-1909$, p. 63; BSTPM, $E F, 02-04-1909$, p. 178.
} 
este pueblo, inmediatamente a su llegada repartió volantes anunciando frente a la parroquia la apertura de una escuela nocturna con el nombre "Miguel Hidalgo", en la que se matricularon 35 niños; esto, a pesar de la advertencia del cura de no "entregar a sus hijos" a esa escuela protestante.

Esta escuela y el taller de zapatos fueron un medio por el cual Liborio se sostuvo económicamente, y como obrero también fue apoyado por los presbiterianos locales. El 15 de septiembre de 1910 se evidenció el perfil del grupo presbiteriano, así como de la misma escuela; a las 4 de la madrugada, en la sede de cultos se sonó la campana para celebrar un culto en conmemoración del centenario de la Independencia. La escuela estrenó su bandera tricolor para amenizar las fiestas patrias cantando el himno nacional y finalizando por la noche con una reunión de temperancia, a la que asistieron más o menos 300 personas, entre ellas gente que no era simpatizante del protestantismo. ${ }^{102}$

Estas manifestaciones patrióticas los colocaban como actores políticos, y no únicamente como religiosos. El presidente de la Junta Patriótica de Muna invitaba a Liborio a pronunciar discursos públicos relativos al tema de la patria, la ciudadanía y la temperancia; sus prédicas dentro del templo lo evidenciaban como un orador bien adiestrado. Esto, a su vez, le permitió tejer redes con los potenciales conversos y posibles adherentes.

Como vimos, Plácido Lope fue líder propagandista del gobierno alvaradista. En Muna tuvo al candidato perfecto para coadyuvar a la labor revolucionaria, su mejor amigo, Liborio Blanco, por lo que en las elecciones municipales de 1916 jugó como candidato del naciente Partido Socialista Obrero (PSO), obteniendo el triunfo como presidente municipal de Muna para el periodo 1916-1917. Este acontecimiento político sería un hecho significativo para el protestantismo local, considerando

102 BSTPM, EF, 14-05-1909, p. 283; BSTPM, EF, 21-10-1910, pp. 670-671; BSTPM, $E F, 08-11-1912$, p. 712. 
que en marzo de 1916 se había conformado un Subcomité de Evangelización con los miembros más activos de la iglesia de Muna. ${ }^{103}$ Es decir, existía un organismo bien estructurado para la labor evangelizadora que sería respaldado por el poder político municipal.

Los conflictos no tardaron en aparecer. En el mes de octubre de 1916, Manuel Carrillo demandó a Liborio Blanco por abuso de autoridad, pues según los policías lo arrestaron de manera injusta e infundada por el delito de embriaguez. Carrillo arguyó que las decisiones arbitrarias de Blanco eran impulsadas por desavenencias políticas, pues fue del bando opositor de los socialistas, a quienes se enfrentó "con valor civil". Liborio Blanco respondió dicha referencia con lo siguiente: "debo decir a Ud. que estos ciudadanos son unos humildes hijos de la localidad que no han representado ni pueden representar papel importante en asuntos políticos". Liborio tenía la identidad de fiel revolucionario y, colocando a Manuel Carrillo como argumedista, la querella terminó por no ser admitida. ${ }^{104}$

Como presidente municipal combatió el alcoholismo por su apego estricto a la Ley de Alcoholes emitida por Alvarado y por sus creencias protestantes. Estas acciones políticas ocasionaron constantes disgustos con los pobladores que vendían y consumían aguardiente de manera cotidiana y festiva. Los rivales argüían su posición como predicador de la iglesia presbiteriana como una falta a la Constitución, pero Plácido Lope exponía sus razones en el periódico La Reforma Social, manifestando que no era ministro pues no poseía los estudios teológicos para ser

103 Este subcomité se conformó por Marcelino Pacheco G. (presidente), Tiburcio Polanco (tesorero), Porfirio Couoh (secretario), Claudio Martín, Pedro Lara S., Aurora Martínez, Margarita Che, Pedro A. Romero, Laureano González, Jacoba Chalé P. y Onesífora Domínguez (vocales): BSTPM, EF, 12-05-1916, p. 309.

104 AGEY,J, P, v. 56, e. 30, 1916-1917. 
ordenado como reverendo. ${ }^{105}$ La directiva de la Liga de Resistencia de Muna “Benito Juárez” también publicó su réplica para que no renunciase Liborio Blanco a la presidencia municipal, la cual finalizaría en diciembre de 1917:

Por lo tanto, el C. Liborio Blanco R. es el representante legal de este Municipio y como tal no ha hecho más q. sentar un principio digno de elogio y quizá el único en el Estado que ha sabido representar dignamente al pueblo que lo eligió, haciendo valer los votos depositados a su favor en los comicios electorales. Y nosotros, los ofendidos por la ilegal pretensión del Comité Constitucionalista de esta Villa, hemos suplicado a nuestro ungido en los comicios de septiembre que por ningún motivo se separa de su puesto de Presidente Municipal porque sería sentar un mal principio, pues la convocatoria del Primer Jefe establece claramente en su Artículo $3^{\circ}$ que los electos DURARÁN SU ENCARGO TODO EL AÑO DE 1917. ${ }^{106}$

Estaba claro que Liborio Blanco no pensó renunciar a la presidencia municipal, ya que ésta era una oportunidad de que un presbiteriano retuviera el poder político. Este conflicto obligadamente también se trasladó a los asuntos religiosos. La fiesta patronal del Cristo de Uxmal ya estaba cerca; el presidente municipal Cáceres y los notables solicitaron un permiso al gobernador para realizar dicha fiesta, pero los socialistas se oponían a dicha celebración, por lo que también mandaron un comunicado a la Liga Central de Resistencia al respecto. Los socialistas locales, desesperados por la inexistente resolución, ingresaron a la iglesia católica el 6 de mayo de 1919 y extrajeron la imagen del Cristo de Uxmal. No obstante, sin encontrar culpables del delito se celebró la fiesta en honor al Cristo de Uxmal

105 BY, FR, La Reforma Social, 01-09-1917, p. 3.

106 BY, FR, La Reforma Social, 01-09-1917, p. 4. 
en el barrio de San Bernardo el 27 de mayo de 1919.107 Los socialistas munenses no estuvieron contentos con esta batalla perdida frente a los liberales católicos y comerciantes.

El contexto político ríspido entre el partido socialista y el partido liberal se sumó a los resentimientos, pues los primeros se adhirieron a la candidatura de Obregón y los segundos a la de Carranza. Esto ocasionó un choque violento en 1919, en el que hubo varios muertos y heridos, así como casas incendiadas; el resultado fue la aprehensión de los socialistas de Muna en el mismo año, los cuales fueron cerca de 50, entre ellos Liborio Blanco, que fue llevado al Cuartel de Dragones.

\section{PRESBITERIANISMO Y HACIENDAS:}

¿INCONGRUENCIA?

La preferencia política de los protestantes hacia la Revolución no sólo obedeció a las afinidades doctrinarias antes mencionadas, sino también a motivos más pragmáticos y económicos. La siguiente referencia es clara al respecto:

El Problema Agrario en su relación con el Sostenimiento de las Congregaciones.- Asunto que parecía ageno [sic] de este Presbiterio, después de un ensayo leído en aquella reunión, se demostró que era de vital interés bajo algunos puntos de vista. La distribución de terrenos al pueblo en general, alcanzará también a nuestros hermanos deseosos de poseer un pedazo de tierra que cultivar y hacer producir. La realización de este ideal aumentará el número de los verdaderos agricultores, y por consecuencia mejorará la situación económica de muchos hermanos, estando en condiciones de subvenir con liberalidad a las necesidades de su culto. [...] Se acordó que cada obrero procurase la posesión de algún terrenito en el que establecer algunos cultivos regionales, que sirviera a guisa

107 Solís, “El Cristo de Uxmal”, pp. 141-142. 
de bosquejos de granjas experimentales, y de ejemplo a los demás hermanos, estimulándolos a mirar con placer el cultivo de la tierra; dándoles a la vez algunas conferencias sobre el asunto. ${ }^{108}$

El momento de la enunciación de este acuerdo no pudo ser más oportuno, fue a principios de 1916, durante una reunión del Presbiterio del Golfo celebrada en Progreso. Por un lado, este dato nos confirma su adhesión al programa político económico del movimiento alvaradista, y por otro, nos llevaría a inferir que los presbiterianos yucatecos siempre fueron críticos del imperante sistema hacendario en el estado. Pero no fue así, años atrás tenían percepciones opuestas sobre la existencia de las haciendas. La impresión del pastor tabasqueño Eligio Granados durante su visita a Yucatán cuatro años antes, es muy sugerente; él escribió que "cada hacienda o quinta es un precioso oasis que atrae con sus verdes encantos, la oriental comodidad de sus viviendas y el franco, caballeroso trato de sus dueños, tan progresistas como laboriosos”. ${ }^{109}$ Para Granados, la hacienda henequenera era la única fuente que permitía dinamizar la vida económica de todo un estado, aunado a sus dueños que eran los motores e impulsores del progreso. En esta concepción, la sujeción laboral de los jornaleros y peones no era vista como esclavitud; por tanto, no había condiciones que tuvieran que ser modificadas o eliminadas.

No obstante, estos halagos tenían una razón de ser para la estrategia proselitista. Los obreros y ministros sabían que gran parte de la población radicaba en las haciendas y que los dueños tenían una buena capacidad de convocatoria; por tanto, era necesario encontrar las formas de predicar el mensaje religioso dentro de estos otros pequeños mundos sociales y también de conseguir cooperación de los 'amos' para la propaganda

108 BSTPM, EF, 17-04-1916, p. 250.

109 BSTPM, $E F, 17-05-1912$, p. 310. 
evangelística. Esto es visible cuando el que fuera el jefe del propagandismo revolucionario escribe en 1912 un ensayo sobre “¿cómo interesar a las clases elevadas de la sociedad en favor del Evangelio puro de Cristo...?”. Por clases elevadas se refería a la clase hacendaria; según Lope, el discurso debía dirigirse a persuadir al amo de "que el Evangelio es el único que puede darles sirvientes sanos, útiles y fieles en el cumplimiento del deber"; y prosigue diciendo: "El hacendado no quiere perder a sus sirvientes, tampoco quiere que éstos sigan en la embriaguez, y como anda en busca de un remedio eficaz y práctico, podrá interesarle saber las maravillas que el Evangelio ha obrado en los hombres". ${ }^{110} \mathrm{Si}$ bien se ha dicho que los hacendados encontraron en el catolicismo un medio de control social sobre los trabajadores, los protestantes estaban dispuestos a ofrecer el evangelio presbiteriano para cumplir este mismo acometido.

Este fin proselitista fue alimentado entre los quehaceres de los ministros cuando en 1909 Francisco Blanco R. tuvo que mudar su residencia a la hacienda San Francisco de los Manzanilla, cerca de Dzidzantún. Alrededor de 1904, esta hacienda era técnicamente la más moderna de Yucatán, con tres máquinas desfibradoras, una escuela y un complejo hospitalario; pero las deudas también eran las más altas, el promedio de deuda era de 254 pesos y el importe máximo ascendió a 821.42. ${ }^{111}$

Francisco Blanco no sólo compartía el nombre con la hacienda, sino también la percepción del progreso. Podemos suponer que Francisco Blanco R. estaba contento de trabajar en la hacienda más moderna de su momento, ya que él formaba parte de este proceso progresista. Pero faltaba algo en la ecuación de la modernidad y el progreso: el protestantismo. Desde el inicio de su trabajo, Francisco platicó con el dueño y con los jornalerospeones sobre los beneficios del evangelio; esto no fue fácil, pero

110 BSTPM, EF, 17-05-1912, p. 314.

111 NiCkel, Elpeonaje en las haciendas mexicanas, pp. 288-289. 
logró conseguir algunos simpatizantes e invitó a sus correligionarios a realizar cultos en la hacienda. Asunción B., Andrés Cardós y esposa, Mauricio Herrera y Leandro Pérez salieron rumbo a la hacienda el 8 de febrero de 1909. Éste sería el primer culto presbiterano celebrado en una hacienda de Yucatán. Al llegar fueron recibidos por el "joven ilustrado y caballero Sr. Lorenzo Manzanilla”, quien les ofreció facilidades logísticas para el culto, al que concurrieron cerca de 100 personas. Así también celebraron otro culto en la casa de Félix S. Manzanilla ubicada en Dzidzantún con la misma concurrencia, donde Asunción predicó frente a este nuevo público. Posteriormente, salieron a vender Biblias y folletos en la hacienda y en el pueblo. A partir de este año hasta finales de 1912 continuaron las visitas proselitistas a la hacienda, ya que el propietario mandó suspender la realización de cultos hasta nuevo aviso. ${ }^{112}$

La hacienda de los Manzanilla fue una de las pocas que pudieron visitar durante esos años. Notaron que era casi imposible acceder si no era por la solicitud de un trabajador de la misma hacienda. Sin embargo, la experiencia con la hacienda San Francisco les hizo ver la importancia de acceder a estos campos para la labranza de la 'palabra de Dios'. No tenían mucho éxito en las haciendas, por eso les fue importante reflexionar sobre las posibles estrategias, las cuales hoy podemos rescatar del ensayo de Lope, quien dijo: "esas clases elevadas han permanecido indiferentes ante el gran edificio del cristianismo [...] y nos demuestran que nada saben del Evangelio y por lo tanto no les interesa". ${ }^{113}$ En efecto, durante los años de 1913-1917 no realizó ninguna visita a alguna hacienda; sólo Lope visitó dos haciendas en 1910 a petición de los peones coreanos, donde bautizó a 45 adultos y 27 niños. ${ }^{114}$

112 BSTPM, EF, 05-03-1909, p. 158; 02-04-1909, p. 178; 15-08-1913, p. 500.

113 BSTPM, $E F, 17-05-1912$, p. 314 [cursiva mía].

114 BSTPM, EF, 05-05-1911, p. 286. 
Fue hasta el año de 1918 cuando de nuevo incursionaron en otra hacienda, en esta ocasión en las ruinas de Aké, por invitación de un hombre llamado Serapio Galaz, aunque la fuente no especifica si éste era miembro o simpatizante. Pero por la información que Asunción Blanco proporciona, se puede saber que en esta hacienda ya existían "algunos creyentes muy fieles". ${ }^{115}$

Por un lado, en los casos vistos en este apartado se puede notar que Asunción Blanco mantuvo la perspectiva de 1912 aún después de la Revolución, en contraste con el cambio de percepción de Plácido Lope como agente revolucionario. Posiblemente, los intereses pragmáticos de los protestantes produjeron esta disonancia entre el discurso y la práctica que hallamos en los archivos.

Por el otro, para los presbiterianos, el programa revolucionario podía eximirse de algunos puntos ideológicos según las necesidades; en este caso no lo fue la temperancia ni la educación, pero sí la crítica al sistema hacendario. Aunque sabemos que Alvarado tampoco realizó una reforma contundente contra los hacendados, ya que necesitó cuidar intereses económicos, alineándose más hacía una "revolución burguesa" ${ }^{116}$ No obstante, el discurso favorecedor hacia los hacendados y la hacienda por parte de los presbiterianos respondió a una estrategia que les permitía simpatizar y acceder a estos centros poblacionales.

\section{CONSIDERACIONES FINALES}

La inserción presbiteriana en Yucatán durante el siglo XIX respondió a la alianza liberal, a la oposición yucateca con el centro político y al vínculo con el sector político-religioso anticatólico. ${ }^{117}$ La relación con los grupos espiritistas también

115 BSTPM, EF, 10-05-1918, p. 299.

116 Joseph, Revolución desde afuera.

117 May May, "Presbiterianos en Yucatán”, pp. 53-65. 
fue evidente, aunque ambos fueron distantes, en tanto que el parentesco masónico fue más difícil de precisar. Aun así, estas características son esenciales en la explicación de Bastian sobre la difusión regional del protestantismo histórico. ${ }^{118}$ Como mencioné al inicio de este texto, éste es el precedente que también argumenta la participación protagónica de los protestantes durante la Revolución y el Constitucionalismo. Sin embargo, para el caso de Yucatán no significó un antecedente causal, puesto que estas alianzas fueron débiles, difusas, interrumpidas y opuestas.

El bloque espiritista, masón y presbiteriano no tuvo cohesión durante la gestión de Alvarado. Incluso hubo cierta oposición constante entre la facción revolucionaria masónica y la protestante, en la que los primeros ejercieron una gran influencia dentro del gobierno, gestando el partido político socialista y liderando a las sociedades obreras. Así también, la interpretación de Jesús como socialista y revolucionario no fue compartida ni aceptada por las figuras prominentes de la Liga de Estudiantes de Yucatán. Es evidente que esto debilitó la posible injerencia e influencia presbiteriana en el gobierno de Alvarado, manifestada en la clara negación de las tres solicitudes hechas por el pastor Plácido Lope. Por tanto, los masones y algunos revolucionarios limitaron la participación de la congregación presbiteriana, algo que no sucedió en el centro del país. Sin embargo, la marginalidad política y el distanciamiento con las sociedades de ideas disidentes locales no obstruyeron el crecimiento ni la difusión del presbiterianismo, tal como señalé al principio.

Entonces, debe decirse que la intervención presbiteriana en la Revolución fue a través de sus individualidades. Pastores, ministros y algunos predicadores se involucraron en los círculos revolucionarios. No obstante, los individuos más notorios no eran de Yucatán, como Plácido Lope, su esposa Ester Labastida,

118 Bastian, Los disidentes. 
Estanislao Llera y los misioneros estadounidenses. Los nacidos en Yucatán fueron Ciriaco Cauich y los hermanos Asunción y Liborio Blanco; los dos primeros fueron formados e instruidos en el Seminario de la Ciudad de México, en tanto Liborio, cercano colaborador de ambos, fue muy influenciado por la formación político-religiosa de su hermano Asunción y por la del pastor Plácido Lope.

Se ha consensuado que las razones del involucramiento presbiteriano en este periodo bélico fueron los objetivos en común, los cuales se evidenciaron en el programa antialcohólico, educativo y en el discurso de la prensa. Sin embargo, para nuestro caso, tal vez tengan que especificarse mejor los motivos de su apoyo al gobierno de Ávila y de Alvarado: los presbiterianos se adhirieron a estos gobiernos por ser revolucionarios. Pareciera redundante, pero con esto quiero decir que los protestantes ya se sentían revolucionarios antes de la llegada de ambos generales; es decir, el puente de compatibilidad entre lo revolucionario y lo protestante ya estaba preconfigurado. Este aspecto está relacionado con lo dicho en el párrafo anterior, pues los detentores de las ideas revolucionarias y los organizadores de los programas y estrategias de inclusión política del presbiterianismo en Yucatán fueron actores foráneos y, en el caso contrario, fueron yucatecos instruidos teológicamente en las instituciones presbiterianas del centro del país.

El programa presbiteriano ha sido bien dibujado por Bastian, ${ }^{119}$ un discurso liberal relacionado con la temperancia y el ensalce patriótico de los héroes de la independencia, todo esto vinculado a un proyecto educativo con fines del establecimiento de escuelas. En Mérida, Progreso, Ticul y Muna fue evidente el esfuerzo por la instauración de este programa. En principio fue promovido por Alfonso Herrera y su esposa Natalia Salcedo,

119 Bastian, Los disidentes. 
ambos provenientes del centro del país, y posteriormente por los ya mencionados.

Considerando lo antes dicho, tenemos que decir que el presbiterianismo anticipó la revolución constitucionalista de Ávila y de Alvarado; las ideas revolucionarias llegaron antes a Yucatán mediante el presbiterianismo. No obstante, tenemos que coincidir con la premisa de Joseph de que fue una "Revolución desde afuera", puesto que el proyecto revolucionario presbiteriano también fue organizado por sujetos externos o instruidos fuera de Yucatán.

\section{SIGLAS Y REFERENCIAS}

AGEY, J, P Archivo General del Estado de Yucatán, fondo Justicia, serie Penal, Mérida, Yucatán.

AGEY, PE, A Archivo General del Estado de Yucatán, fondo Poder Ejecutivo, sección Ayuntamientos, Mérida, Yucatán.

AGEY, PE, EP Archivo General del Estado de Yucatán, fondo Poder Ejecutivo, sección Educación Pública, Mérida, Yucatán.

AGEY, PE, G Archivo General del Estado de Yucatán, fondo Poder Ejecutivo, sección Gobernación, Mérida, Yucatán.

AGEY, PE, G, C Archivo General del Estado de Yucatán, fondo Poder Ejecutivo, sección Gobernación, serie Correspondencia, Mérida Yucatán.

AHAY, G, C Archivo Histórico del Arzobispado de Yucatán, sección Gobierno, serie Correspondencia, Conkal, Yucatán.

BFBS British and Foreign Bible Society.

BSTPM, EF Biblioteca del Seminario Teológico Presbiteriano de México, El Faro, Ciudad de México.

BY, FR, Biblioteca Yucatanense, Fondo Reservado, Mérida, Yucatán.

SBA Sociedad Bíblica Americana.

Álvarez Cuartero, Izaskun, “Hacer patria sin indios. De los sanjuanistas a la guerra de castas, 1812-1847”, en Chust y FrAsQuet (eds.), 2009, pp. 171-196.

Alvear Acevedo, Carlos, La Iglesia en la historia de México, México, Jus, 1975. 
ArgüElles, Luz Verónica, "El protestantismo en Yucatán a través de los medios periodísticos de la época: 1875-1885”, monografía de licenciatura en historia, Mérida, Yuc., Universidad Autónoma de Yucatán, 2005.

BaILEY, David, "Revisionism and the Recent Historiography of the Mexican Revolution", en The Hispanic American Historical Review, 58: 1 (1978), pp. 62-79.

Balam, Yuri H., La masonería en Yucatán. El caso de la Gran Logia Unida "La Oriental Peninsular", Mérida, Yuc., Universidad Autónoma de Yucatán, 1996.

BALDwin, Deborah, “Diplomacia cultural: escuelas misionales protestantes en México”, en Historia Mexicana, xxxvi: 2 (142) (oct.-dic. 1986), pp. 287-322.

Baldwin, Deborah, Protestants and the Mexican Revolution. Missionaries, ministers and social change, Chicago, University of Illinois Press, 1990.

BaqueIro, Serapio, Historia del antigno Seminario Conciliar de San Ildefonso, Mérida, Yuc., Tipografía de G. Canto, 1984.

Bastian, Jean Pierre, Protestantismo y sociedad en México, México, Casa Unida de Publicaciones, 1983.

BASTIAN, Jean Pierre, "La penetración de las sociedades protestantes religiosas norteamericanas en México, 1872-1876”, en Taller de Teología, 14 (1984), pp. $5-30$.

Bastian, Jean Pierre, Historia del protestantismo en América Latina, México, Casa Unida de Publicaciones, 1986.

BASTIAn, Jean Pierre, "El paradigma de 1789. Sociedades de ideas y Revolución mexicana”, en Historia Mexicana, xxxviII: 1 (149) (jul.-sep. 1988), pp. 79-110.

Bastian, Jean Pierre, Los disidentes. Sociedades protestantes y revolución en México, 1872-1911, México, Fondo de Cultura Económica, 1989.

Bautista, Cecilia A., "Hacia la romanización de la Iglesia mexicana a fines del siglo xIX", en Historia Mexicana, Lv: 1 (217) (jul.-sep. 2005), pp. 99-144.

Blanco, Asunción, Breve reseña histórica de la Iglesia presbiteriana de Ticul, Yuc., s. l., s. e., 1952. 
CARR, Barry, "Recent Regional Studies of the Mexican Revolution”, en Latin American Research Review, 15: 1 (1980), pp. 3-14.

Carrillo y Ancona, Crescencio, "Orden Circular contra la propaganda protestante”, Mérida, Imprenta de la Revista de Mérida, 1885.

Chacón, Ramón D., "Salvador Alvarado and the Roman Catholic Church: Church-State Relations in Revolutionary Yucatán, 1914-1918”, en Journal of Church and State, 27: 2 (1985), pp. 245-266.

Chust, Manuel e Ivana Frasquet (eds.), Los colores de las independencias iberoamericanas. Liberalismo, etnia y raza, Madrid, Consejo Superior de Investigaciones Científicas, 2009.

DíAz GüEMEs, Marco A., "El arte monumental del socialismo yucateco (19181956)", tesis de doctorado en historia, Mérida, Yuc., Centro de Investigaciones y Estudios Superiores en Antropología Social-Peninsular, 2014.

FALLAw, Ben, "The seduction of Revolution: anticlerical campaigns against confession in Mexico, 1914-1935”, en Journal of Latin American Studies, 45: 1 (2013), pp. 91-120.

González, Marcela, "La imprenta en la península de Yucatán en el siglo xix”, tesis de doctorado en historia, Mérida, Yuc., Centro de Investigaciones y Estudios Superiores en Antropología Social-Peninsular, 2014.

Joseph, Gilbert, Revolución desde afuera. Yucatán, México y los Estados Unidos, 1880-1924, México, Fondo de Cultura Económica, 1992.

Koyock, José, "Sin abrigo ni pan: los braceros mexicanos en las plantaciones de henequén de Yucatán (1916-1922)", tesis de maestría en historia, Mérida, Yuc., Centro de Investigaciones y Estudios Superiores en Antropología SocialPeninsular, 2016.

Loza Álvarez, Aura, "La influencia del romanticismo cristiano en la configuración estética del paisaje yucateco y su imaginario social", en TARACENA (ed.), Depetris y Sellen (comps.), 2013, pp. 251-272.

Mantilla, Jorge, "El pensamiento sanjuanista en el proceso de Independencia", en Revista de la Universidad Autónoma de Yucatán, 229 (2004) pp. 51-65.

Martín DíAz, Josefa, "Experiencias de las asociaciones femeniles evangélicas en el Sureste de México, 1870-1960", tesis de doctorado en historia, Mérida, 
Yuc., Centro de Investigaciones en Estudios Superiores en Antropología Social-Peninsular, 2014.

Martín Díaz, Josefa, "Origen del protestantismo en Yucatán y su relación con las sociedades liberales, 1867-1900”, tesis de maestría en etnohistoria, Mérida, Yuc., Universidad Autónoma de Yucatán, 2004.

Martín DíAz, Josefa, Historia de la Iglesia presbiteriana en Yucatán, Mérida, Yuc., Editorial de la Peninsular, 2000.

Martínez, Carlos, "Regreso de Diego Thomson a México: 1842-1844”, en Protestante Digital (19-07-2015). http://protestantedigital.com/magacin/36827/regreso_de_diego_thomson_a_mexico_1842_1844. Consultado el 15 de agosto de 2016.

May May, Ezer Roboam, "Presbiterianos en Yucatán. Hacia un estudio microhistórico del crecimiento protestante 1900-1940", tesis de maestría en historia, México, Centro de Investigaciones y Estudios superiores en Antropología Social, 2017.

McKechnie, Marian E., "The Mexican Revolution and the national Presbyterian church of Mexico, 1910-1940”, tesis de doctorado en historia, Washington, The American University, 1970.

Menéndez, Hernán, Iglesia y poder. Proyectos sociales, alianzas políticas y económicas en Yucatán (1857-1917), México, Escuela Nacional de Antropología, Conaculta, 1995.

Nickel, Herbert J., El peonaje en las haciendas mexicanas. Interpretaciones, fuentes, hallazgos, México, Arnold Bergstraesser Institut, Universidad Iberoamericana, 1997.

Paoli Bolio, Francisco José et al., La Revolución en Yucatán. Nuevos ensayos, Mérida, CEPSA, 2012.

Quezada, Sergio e Inés OrTiz (coords.), Yucatán en la ruta del liberalismo mexicano, siglo XIX, Mérida, Yuc., Universidad Autónoma de Yucatán, 2008.

Ramírez, José D., Jesús ante la moral y el socialismo, México, Imprenta Francesa-Jardín Carlos Pacheco números 1 y 3, 1916.

Rugeley, Terry, De milagros y sabios. Religión y culturas populares en el sureste de México, 1800-1876, Mérida, Yuc., Universidad Autónoma de Yucatán, 2012. 
SAVARINo, Franco, "Yucatán: ¿un caso atípico en la Revolución Mexicana?", en PaOli Bolio et al., 2012, pp. 83-128.

Savarino, Franco, Pueblos y nacionalismo. Del régimen oligárquico a la sociedad de masas en Yucatán, 1894-1925, México, Instituto Nacional de Estudios Históricos de las Revoluciones de México, 1997.

SoLís, Iván, "El Cristo de Uxmal: historia, celebración y conflicto de una fiesta patronal en el Pú'uk", en Estudios de Cultura Maya, 41 (2013), pp. 129-155.

SuÁrez, Víctor M., Historia del obispado y arzobispado de Yucatán, siglos XIX y XX, Mérida, Fondo Editorial de Yucatán, 1981, t. III.

Taracena, Arturo, “El Museo Yucateco y la reinvención de Yucatán. La prensa y la construcción del regionalismo peninsular”, en Peninsula, 2: 1 (2007), pp. 13-46.

Taracena, Arturo, "Lo político en el periodismo literario. La visión regionalista en El Museo Yucateco y el Registro Yucateco, 1841-1849”, en QueZada y ORTIZ (coords.), 2008, pp. 219-243.

Taracena, Arturo (ed.), Carolina Depetris y Adam T. Sellen (comps.), Miradas regionales. Las regiones y la idea de nación en América Latina, siglos XIX y XX, Mérida, Yuc., Universidad Nacional Autónoma de México, 2013.

Vega y Ortega Báez, Rodrigo A., "La óptica metodista en la divulgación de la medicina científica. El Abogado Cristiano Ilustrado, 1877-1910", en eä journal, 1, 2 (2009), pp. 1-25. http://www.ea-journal.com/art1.2/Opticametodista-en-la-divulgacion-de-medicina-El-Abogado-Cristiano-Ilustrado. pdf. Consultado el 10 de octubre de 2016. 